九州大学学術情報リポジトリ

Kyushu University Institutional Repository

\title{
NOTE ON THE EFFECT OF A PERMUTATION IN MAXMINIMIZATION BY A SEQUENCE OF FUNCTIONS
}

Maruyama, Fumio

Faculty of Engineering, Tohwa University

https://doi.org/10.5109/25903

出版情報: Bulletin of informatics and cybernetics. 42, pp.15-33，2010-12. Research Association of Statistical Sciences

バージョン:

権利関係 : 
NOTE ON THE EFFECT OF A PERMUTATION IN MAXMINIMIZATION BY A SEQUENCE OF FUNCTIONS

by

Fumio Maruyama

Reprinted from the Bulletin of Informatics and Cybernetics Research Association of Statistical Sciences, Vol.42

FUKUOKA, JAPAN

2010 


\title{
NOTE ON THE EFFECT OF A PERMUTATION IN MAXMINIMIZATION BY A SEQUENCE OF FUNCTIONS
}

\author{
By
}

Fumio MARUYama*

\begin{abstract}
We consider maxminimizations (minmaximizations) of functions of several variables defined on a Cartesian product of finite sets under some dependence conditions between variables. The effects of the combinations of dependence conditions between variables and permutations of optimizations on equilibrium values are rather complicated. We show an example to catch a glimpse of the intricacies.
\end{abstract}

Key Words and Phrases: Equilibrium, Order.

\section{Introduction}

Under some conditions a sequence of operations either maximization or minimization subject to variables applied to a real valued function of several variables gives a real number - an equilibrium value. For a natural number $n$ let $C\left(I^{n}\right)$ be the set of real valued continuous functions on $I^{n}$ where $I$ is the unit interval of the real line and let $\Sigma_{n}$ be the set of functionals that maps each element of $C\left(I^{n}\right)$ to such an equilibrium value. For example if $n=2$,

$$
\Sigma_{2}=\left\{\max _{z_{1}} \max _{z_{2}}, \max _{z_{1}} \min _{z_{2}}, \max _{z_{2}} \min _{z_{1}}, \min _{z_{1}} \max _{z_{2}}, \min _{z_{2}} \max _{z_{1}}, \min _{z_{1}} \min _{z_{2}}\right\}
$$

Here, for example, $\max _{z_{1}} \min _{z_{2}}$ is the functional given by $\max _{z_{1}} \min _{z_{2}}(F)=\max _{z_{1}} \min _{z_{2}} F\left(z_{1}, z_{2}\right)$ for $F \in C\left(I^{2}\right)$ where maximization and minimization are taken over all elements in I. $\Sigma_{n}$ is an ordered set by the pointwise order. In Hisano and Maruyama (1989) we studied this order. There in Theorem 4.6 we proved that for $\sigma_{1}, \sigma_{2}, \ldots, \sigma_{m} \in \Sigma_{n}$, if an arbitrary given order $\sigma_{1}<\sigma_{2}<\cdots<\sigma_{m}$ does not contradict the order on $\Sigma_{n}$, there exists $F \in C\left(I^{n}\right)$ such that $\sigma_{1}(F)<\sigma_{2}(F)<\cdots<\sigma_{m}(F)$. This means that on $\Sigma_{n}$ there exists no logical structure except the trivial one.

In the present paper, we treat the problem of maxminimization (minmaximization) by a sequence of variable functions. That is, to a function of several variables, when each variable is a function - a variable function - of some variables, we apply a sequence of optimal operations by these variable functions. In the case of maxminimization by a sequence of variables, the role - either maximization or minimization - of each variable and the dependence between variables determine the equilibrium value. The operation order of variables and the dependence between variables are united so a change in order of operations changes the dependence. On the other hand, in the case of maxminimization

\footnotetext{
* Faculty of Engineering, Tohwa University, Fukuoka 815-8510, Japan. tel +81-92-541-1152
} 
by a sequence of variable functions, there exists a change in order of operations that holds the dependence between variables but causes difference in the equilibrium values. It is easy to find such an example.

Let $D$ be the set consists of 0 and 1 and let $G$ the mapping from $D^{4}$ into $D$ such that $G^{-1}(1)=\{(0,0,0,0),(0,0,1,1),(0,1,0, *),(1,1,1, *)\}$ where $*$ is either 0 or 1 . In the following maxminimization let $f_{1}, f_{2}$ and $f_{4}$ be taken from all mappings from $D$ into $D$ and let $z_{3}$ be taken from $D$. Then

$$
\begin{gathered}
\max _{f_{1}} \min _{f_{2}} \min _{f_{4}} \max _{z_{3}} G\left(f_{1}\left(f_{2}\left(z_{3}\right)\right), f_{2}\left(z_{3}\right), z_{3}, f_{4}\left(f_{1}\left(f_{2}\left(z_{3}\right)\right)\right)\right)=0, \\
\min _{f_{2}} \max _{f_{1}} \min _{f_{4}} \max _{z_{3}} G\left(f_{1}\left(f_{2}\left(z_{3}\right)\right), f_{2}\left(z_{3}\right), z_{3}, f_{4}\left(f_{1}\left(f_{2}\left(z_{3}\right)\right)\right)\right)=1 .
\end{gathered}
$$

To verify the first equality set $f_{2}$ and $f_{4}$ according to $f_{1}$ as follows. If $f_{1}(0)=1$ then $f_{2}(0)=f_{2}(1)=0$. Otherwise $f_{2}(0)=f_{1}(1)$ and $f_{2}(1)=f_{4}(0) \neq f_{1}(1)$. To verify the second, set $f_{1}$ and $z_{3}$ according to $f_{2}$ as follows. If there exists some $k$ such that $f_{2}(k)=1$ then $f_{1}(1)=z_{3}=k$. Otherwise $f_{1}(0)=0$ and $z_{3}=f_{4}(0)$. For the functionals of this sort, we use a shorthand notation like $x_{1}\left(y_{2}\right) y_{2}\left(x_{3}\right) y_{4}\left(x_{1}\right) x_{3}, y_{2}\left(x_{3}\right) x_{1}\left(y_{2}\right) y_{4}\left(x_{1}\right) x_{3}$ for the above for example.

In maxminimization by a sequence of variable functions, the elements that determine the equilibrium value are the roles of variables, the dependence between variables and the operation order of variable functions. The power of the first two elements is clear. But the power of operation order of variable functions to equilibrium value is obscure. Varing other factors that affect the equilibrium value, how much power, in the ultimate, does an exchange of operation order of two variable functions have? Before a systematic investigation, let us observe it by a concrete example of moderate complexity. In this paper we give a limit example of three maximizers and three minimizers case.

For a positive integer $N$, let $\mathcal{D}_{N}$ be the set of all Cartesian products of $N$-finite sets and let $\mathcal{F}_{N}$ be the set of all real valued functions with domain in $\mathcal{D}_{N}$. An $N$ length sequence of optimizations by variable functions maps each element of $\mathcal{F}_{N}$ to an equilibrium value. We call such a functional an equilibrium functional of $N$-variables. In Section 2 we give a precise definition of an equilibrium functional and in Example 2.1 we give a pair of equilibrium functionals on $\mathcal{F}_{6}$ that shows the power of an order exchange of two variable functions. Varing other factors that affect the equilibrium value, we verify that this pair is a limit pair that shows the power limit of an order exchange of two variable functions. In Section 3 we construct a function - a separating function - in $\mathcal{F}_{6}$ which separates the values of the two functionals of Example 2.1 by the effect of the order exchange of two variable functions and provide a proof.

\section{Equilibrium functionals}

Definition 2.1. Let $N$ be a positive integer let $\pi$ be a permutation of $[1, N]$ (where for integers $m, n,[m, n]$ denotes $\{m, m+1, \ldots, n\})$ and let $\theta$ be a mapping from $[1, N]$ into $[0,1]$. Let $\Upsilon=\left(\Upsilon_{1}, \Upsilon_{2}, \ldots, \Upsilon_{N}\right)$ be a sequence of subsets of $[1, N]$ such that no $m, n_{1}, n_{2}, \ldots, n_{m} \in[1, N]$ satisfy $n_{1} \in \Upsilon_{n_{2}}, n_{2} \in \Upsilon_{n_{3}}, \ldots, n_{m-1} \in \Upsilon_{n_{m}}, n_{m} \in \Upsilon_{n_{1}}$. A triple $(\pi, \theta, \Upsilon)$ is called an equilibrium functional of $N$-variables. The set of all equilibrium functionals of $N$-variables is denoted by $\mathcal{E}_{N}$.

Definition 2.2. Let $\sigma=(\pi, \theta, \Upsilon) \in \mathcal{E}_{\mathcal{N}}$ and let $F \in \mathcal{F}_{\mathcal{N}}$ with domain $\prod_{n \in[1, N]} Z_{n}$. For 
each $n \in[1, N]$ let $h_{n}$ be a function from $\prod_{u \in \Upsilon_{n}} Z_{u}$ into $Z_{n}$. We define $\sigma^{\left(h_{\pi(1)}, h_{\pi(2)}, \ldots, h_{\pi(n)}\right)}$ $(F)(n \in[1, N])$ and $\sigma(F)$ inductively as follows.

$$
\begin{gathered}
\sigma^{\left(h_{\pi(1)}, h_{\pi(2)}, \ldots, h_{\pi(N)}\right)}(F)=F\left(h_{1}\left(\left(z_{u}\right)_{u \in \Upsilon_{1}}\right), h_{2}\left(\left(z_{u}\right)_{u \in \Upsilon_{2}}\right), \ldots, h_{N}\left(\left(z_{u}\right)_{u \in \Upsilon_{N}}\right)\right) \\
\left(\text { where } z_{n}=h_{n}\left(\left(z_{u}\right)_{u \in \Upsilon_{n}}\right)(n \in[1, N])\right), \\
\sigma^{\left(h_{\pi(1)}, h_{\pi(2)}, \ldots, h_{\pi(n-1)}\right)}(F)= \begin{cases}\max _{h_{\pi(n)}} \sigma^{\left(h_{\pi(1)}, h_{\pi(2)}, \ldots, h_{\pi(n)}\right)}(F) & (\theta(\pi(n))=1) \\
\min _{h_{\pi(n)}} \sigma^{\left(h_{\pi(1)}, h_{\pi(2)}, \ldots, h_{\pi(n)}\right)}(F) & (\theta(\pi(n))=0)\end{cases} \\
\sigma(F)= \begin{cases}\max _{h_{\pi(1)}} \sigma^{h_{\pi(1)}}(F) & (\theta(\pi(1))=1) \\
\min _{h_{\pi(1)}} \sigma^{h_{\pi(1)}}(F) & (\theta(\pi(1))=0) .\end{cases}
\end{gathered}
$$

We define an order on $\mathcal{E}_{N}$ by

$$
\sigma \leqslant \sigma^{\prime} \text { if and only if } \sigma(F) \leqslant \sigma^{\prime}(F)\left(F \in \mathcal{F}_{N}\right) .
$$

The following theorem provides a sufficient condition for an alteration in dependence between variables to extinguish the effect of an order exchange of two variable functions.

Theorem 2.1. Let $n \in[1, N-1]$ and let $\sigma=(\pi, \theta, \Upsilon), \sigma^{\prime}=\left(\pi^{\prime}, \theta, \Upsilon^{\prime}\right) \in \mathcal{E}_{N}$ satisfy the following conditions.

(i) $\pi^{\prime}(m) \neq \pi(m)$ if and only if $m \in\{n, n+1\}$.

(ii) $\theta(\pi(n))=0$ and $\theta(\pi(n+1))=1$.

(iii) $\Upsilon_{\pi(n+1)}=\varnothing,\{\pi(n)\} \cup \Upsilon_{\pi(n)} \subset \Upsilon_{\pi(n+1)}^{\prime}$ and $\Upsilon_{\pi(m)}^{\prime}=\Upsilon_{\pi(m)}$ for all $m \in[1, N] \backslash$ $\{n+1\}$.

(iv) $\pi(n+1) \in \Upsilon_{\pi(m)}$ for all $m>n+1$ with $\theta(\pi(m))=1$.

Then $\sigma \leqslant \sigma^{\prime}$.

Proof. No generality is lost by assuming that $\pi$ is the transposition of 1 and $2, \pi^{\prime}$ is the identity and that $\Upsilon_{1}^{\prime}=\{2\} \cup \Upsilon_{2}$. Let $Z_{1}, Z_{2}, \ldots, Z_{N}$ be finite sets and let $F$ be a function from $\prod_{n \in[1, N]} Z_{n}$ into $[0,1]$. It is enough to prove that $\sigma^{\prime}(F)=1$ when $\sigma(F)=1$. It follows from $\sigma(F)=1$ that, for all $g \in^{\left(\prod_{u \in \Upsilon_{2}} Z_{u}\right)} Z_{2}$ (the set of all mappings from $\prod_{u \in \Upsilon_{2}} Z_{u}$ into $\left.Z_{2}\right), \sigma^{g}(F)=1$ and therefore $\left\{z_{1} \in Z_{1} \mid \sigma^{\left(g, z_{1}\right)}(F)=1\right\} \neq \varnothing$. We may suppose $Z_{1}$ is well ordered and define $f_{1}^{g} \in Z_{1}$ as $\min \left\{z_{1} \in Z_{1} \mid \sigma^{\left(g, z_{1}\right)}(F)=1\right\}$. Since

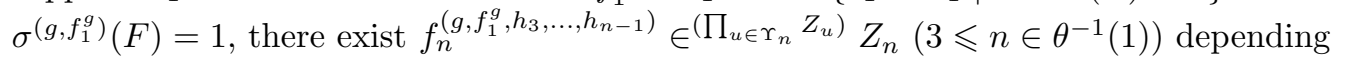


on $h_{1}=f_{1}^{g}, h_{2}=g, h_{3} \in \in^{\left(\prod_{u \in \Upsilon_{3}} Z_{u}\right)} Z_{3}, \ldots, h_{n-1} \in^{\left(\prod_{u \in \Upsilon_{n-1}} Z_{u}\right)} Z_{n-1}$ such that $h_{n}=f_{n}^{\left(g, f_{1}^{g}, h_{3}, \ldots, h_{n-1}\right)}\left(3 \leqslant n \in \theta^{-1}(1)\right)$ implies that

$$
\begin{gathered}
F\left(f_{1}^{g}, g\left(\left(z_{u}\right)_{u \in \Upsilon_{2}}\right), h_{3}\left(\left(z_{u}\right)_{u \in \Upsilon_{3}}\right), \ldots, h_{N}\left(\left(z_{u}\right)_{u \in \Upsilon_{N}}\right)\right)=1 \\
\left(\text { where } z_{m}=h_{m}\left(\left(z_{u}\right)_{u \in \Upsilon_{m}}\right)(1 \leqslant m \leqslant N)\right) .
\end{gathered}
$$

Let $\prod_{u \in \Upsilon_{2}} Z_{u}=\left\{w_{1}, w_{2}, \ldots, w_{M}\right\}$ and let $f \in^{\left(Z_{2} \times \prod_{u \in \Upsilon_{2}} Z_{u}\right)} Z_{1}$ be defined by, for $v \in Z_{2}$ and $w_{m}(1 \leqslant m \leqslant M)$,

$$
\begin{array}{r}
f\left(v, w_{m}\right)=\max _{v_{1}, v_{2}, \ldots, v_{m-1} \in Z_{2}} \min \left\{f_{1}^{g} \mid g \in \in^{\left(\prod_{u \in \Upsilon_{2}} Z_{u}\right)} Z_{2}, g\left(w_{1}\right)=v_{1},\right. \\
\left.g\left(w_{2}\right)=v_{2}, \ldots, g\left(w_{m-1}\right)=v_{m-1}, g\left(w_{m}\right)=v\right\} .
\end{array}
$$

¿From the definitions of $f_{1}^{g}$ and $f$, for $g \in^{\left(\prod_{u \in \Upsilon_{2}} Z_{u}\right)} Z_{2}$ and $z_{1} \in\{f(g(w), w) \mid w \in$ $\left.\prod_{u \in \Upsilon_{2}} Z_{u}\right\}$, there exists $G\left(g, z_{1}\right) \in \in^{\left(\prod_{u \in \Upsilon_{2}} Z_{u}\right)} Z_{2}$ such that

$$
f_{1}^{G\left(g, z_{1}\right)}=z_{1} \text { and } G\left(g, z_{1}\right)(w)=g(w)\left(w \in \prod_{u \in \Upsilon_{2}} Z_{u}, f(g(w), w)=z_{1}\right)
$$

If $3 \leqslant n \in \theta^{-1}(1)$ and if $z_{1}=f\left(g\left(\left(z_{u}\right)_{u \in \Upsilon_{2}}\right),\left(z_{u}\right)_{u \in \Upsilon_{2}}\right)$, since $1 \in \Upsilon_{n}^{\prime}$ by (iv), the maximizer in $\sigma^{\prime}$ can take $h_{n}=f_{n}^{\left(G\left(g, z_{1}\right), f_{1}^{G\left(g, z_{1}\right)}, h_{3}, \ldots, h_{n-1}\right)}$ and hence by (2) and (1)

$$
\begin{gathered}
F\left(f\left(g\left(\left(z_{u}\right)_{u \in \Upsilon_{2}}\right),\left(z_{u}\right)_{u \in \Upsilon_{2}}\right), g\left(\left(z_{u}\right)_{u \in \Upsilon_{2}}\right), h_{3}\left(\left(z_{u}\right)_{u \in \Upsilon_{3}}\right), \ldots, h_{N}\left(\left(z_{u}\right)_{u \in \Upsilon_{N}}\right)\right) \\
\quad=F\left(f_{1}^{G\left(g, z_{1}\right)}, G\left(g, z_{1}\right)\left(\left(z_{u}\right)_{u \in \Upsilon_{2}}\right), h_{3}\left(\left(z_{u}\right)_{u \in \Upsilon_{3}}\right), \ldots, h_{N}\left(\left(z_{u}\right)_{u \in \Upsilon_{N}}\right)\right)=1 .
\end{gathered}
$$

Therefore $\sigma^{\prime f}(F)=1$, hence $\sigma^{\prime}(F)=1$.

Example 2.1. Let $\tau, \mu \in \mathcal{E}_{6}$ be, in the shorthand notation, such that

$$
\begin{aligned}
\tau & =x_{1}\left(y_{2}, y_{4}\right) y_{2}\left(y_{0}\right) x_{3}\left(x_{1}, x_{5}, y_{2}, y_{0}\right) y_{0}\left(y_{4}\right) x_{5}\left(x_{1}\right) y_{4}, \\
\mu & =y_{2}\left(y_{4}, y_{0}\right) x_{1} x_{3} x_{5} y_{4} y_{0} .
\end{aligned}
$$

Then $\mu \nless \tau$.

Let $\tau^{\prime}$ and $\mu^{\prime}$ be modifications of $\tau$ and $\mu$ respectively such that $\tau<\tau^{\prime}$ and $\mu^{\prime}<\mu$. Then $\mu<\tau^{\prime}$ and $\mu^{\prime}<\tau$. In this sence the pair $(\tau, \mu)$ shows the power limit of an order exchange of two variable functions. We prove $\mu<\tau^{\prime}$ and $\mu^{\prime}<\tau$ for several examples of $\tau^{\prime}$ and $\mu^{\prime}$. The proofs for the other cases are similar. Let

$$
\begin{aligned}
\tau_{1} & =x_{1}\left(y_{2}, y_{4}\right) y_{2}\left(y_{0}\right) y_{0}\left(y_{4}\right) x_{3}\left(x_{1}, x_{5}, y_{2}, y_{0}\right) x_{5}\left(x_{1}\right) y_{4} \\
\tau_{2} & =x_{1}\left(y_{2}, y_{4}\right) y_{2}\left(y_{0}\right) x_{3}\left(x_{1}, x_{5}, y_{2}, y_{4}, y_{0}\right) y_{0}\left(y_{4}\right) x_{5}\left(x_{1}\right) y_{4}, \\
\tau_{3} & =x_{1}\left(y_{2}, y_{4}\right) y_{2}\left(y_{0}\right) x_{3}\left(x_{1}, x_{5}, y_{2}, y_{0}\right) y_{0}\left(y_{4}\right) x_{5}\left(x_{1}, y_{2}\right) y_{4}, \\
\tau_{4} & =x_{1}\left(y_{2}, y_{4}, y_{0}\right) y_{2}\left(y_{0}\right) x_{3}\left(x_{1}, x_{5}, y_{2}, y_{0}\right) y_{0}\left(y_{4}\right) x_{5}\left(x_{1}\right) y_{4}, \\
\tau_{5} & =x_{1}\left(y_{2}, x_{4}\right) y_{2}\left(y_{0}\right) x_{3}\left(x_{1}, x_{5}, y_{2}, y_{0}\right) y_{0}\left(x_{4}\right) x_{5}\left(x_{1}\right) x_{4}, \\
\mu_{1} & =y_{2}\left(x_{1}, y_{4}, y_{0}\right) x_{1} x_{3} x_{5} y_{4} y_{0}, \\
\mu_{2} & =y_{2}\left(x_{3}, y_{4}, y_{0}\right) x_{1} x_{3} x_{5} y_{4} y_{0}, \\
\mu_{3} & =y_{2}\left(y_{4}, y_{0}\right) x_{1} x_{3} y_{5} y_{4} y_{0} .
\end{aligned}
$$


Then

$$
\begin{aligned}
\tau_{1} & >x_{1}\left(y_{2}, y_{4}\right) y_{2}\left(y_{4}\right) y_{0}\left(y_{4}\right) x_{3}\left(x_{1}, x_{5}, y_{2}, y_{0}\right) x_{5}\left(x_{1}\right) y_{4} \\
& \left.>y_{2}\left(y_{4}\right) x_{1} y_{0}\left(y_{4}\right) x_{3}\left(x_{5}, y_{2}, y_{0}\right) x_{5} y_{4} \quad \text { by Theorem } 2.1\right) \\
& >\mu \\
\tau_{2} & =x_{1}\left(y_{2}, y_{4}\right) y_{2}\left(y_{0}\right) y_{0}\left(y_{4}\right) x_{5}\left(x_{1}\right) y_{4} x_{3} \\
& >x_{1}\left(y_{2}, y_{4}\right) y_{2}\left(y_{4}\right) y_{0}\left(y_{4}\right) x_{5}\left(x_{1}\right) y_{4} x_{3} \\
& >y_{2}\left(y_{4}\right) x_{1} y_{0}\left(y_{4}\right) x_{5} y_{4} x_{3} \quad(\text { by Theorem } 2.1) \\
& >\mu \\
\tau_{3} & =y_{2} x_{1}\left(y_{4}\right) x_{3}\left(x_{1}, x_{5}, y_{0}\right) y_{0}\left(y_{4}\right) x_{5}\left(x_{1}\right) y_{4}>\mu, \\
\tau_{4} & >y_{2}\left(y_{0}\right) x_{1} x_{3}\left(x_{5}, y_{2}, y_{0}\right) y_{0}\left(y_{4}\right) x_{5} y_{4} \quad(\text { by Theorem } 2.1) \\
& >\mu \\
\tau_{5} & >x_{4} x_{1}\left(y_{2}\right) y_{2}\left(y_{0}\right) x_{3}\left(y_{0}\right) y_{0} x_{5} \\
& =x_{4} y_{2} x_{1} y_{0} x_{3} x_{5} \\
& >y_{4} y_{2} x_{1} y_{0} x_{3} x_{5}>\mu, \\
\mu_{1} & =x_{1} y_{2}\left(y_{4}, y_{0}\right) x_{3} x_{5} y_{4} y_{0}<\tau, \\
\mu_{2} & =x_{3} y_{2}\left(y_{4}, y_{0}\right) x_{1} x_{5} y_{4} y_{0} \\
& <x_{3} y_{2}\left(y_{4}\right) x_{1} x_{5} y_{4} y_{0} \\
& <x_{3} x_{1}\left(y_{2}, y_{4}\right) y_{2}\left(y_{4}\right) x_{5}\left(x_{1}\right) y_{4} y_{0} \quad(\text { by Theorem } 2.1) \\
& <x_{3} x_{1}\left(y_{2}, y_{4}\right) y_{2}\left(y_{4}\right) y_{0}\left(y_{4}\right) x_{5}\left(x_{1}\right) y_{4} \\
& <x_{3} x_{1}\left(y_{2}, y_{4}\right) y_{2}\left(y_{0}\right) y_{0}\left(y_{4}\right) x_{5}\left(x_{1}\right) y_{4}<\tau, \\
\mu_{3} & <y_{2}\left(y_{4}\right) x_{1} y_{0} x_{3} y_{5} y_{4} \\
& <x_{1}\left(y_{2}, y_{4}\right) y_{2}\left(y_{4}\right) y_{0} x_{3}\left(x_{1}\right) y_{5} y_{4} \quad(\text { by Theorem } 2.1) \\
& =x_{1}\left(y_{2}, y_{4}\right) y_{2}\left(y_{4}, y_{0}\right) y_{0} x_{3}\left(x_{1}, y_{0}\right) y_{5} y_{4} \\
& <x_{1}\left(y_{2}, y_{4}\right) y_{2}\left(y_{0}\right) x_{3}\left(x_{1}, y_{0}\right) y_{0} y_{5} y_{4} \\
& =x_{1}\left(y_{2}, y_{4}\right) y_{2}\left(y_{0}\right) x_{3}\left(x_{1}, y_{0}\right) y_{0}\left(y_{4}\right) y_{5} y_{4} \\
& <x_{1}\left(y_{2}, y_{4}\right) y_{2}\left(y_{0}\right) x_{3}\left(x_{1}, y_{0}\right) y_{0}\left(y_{4}\right) x_{5} y_{4}<\tau . \\
&
\end{aligned}
$$

\section{Proof of $\mu \nless \tau$ in Example 2.1}

In Subsection 3.1, by a series of definitions, we construct a Cartesian product $Z$ of six finite sets with internal structure. On the structure we define a separating function $F_{0} \in^{Z}[0,1]$ in Definition 3.12 and prove $\mu\left(F_{0}\right)=1$. In Subsection 3.2 we prove $\tau\left(F_{0}\right)=0$.

\subsection{Construction of a separating function}

Let $U$ be a set and let $n$ be a non-negative integer. We denote by $\sharp U$ the cardinality of $U$, and by $\left(\begin{array}{c}U \\ n\end{array}\right)$ the set of all subsets of $U$ with cardinality $n$. We use $i, j, k, l$ for elements of $[0,1]$ and $p, p^{\prime}$ for elements of $[0,4]$. Calculations concerning only $i, j, k, l$ will be carried out modulo 2 , and calculations concerning $p, p^{\prime}$ will be carried out modulo 5 . 
Definition 3.1. We define $X_{1,0}, X_{1,1}, X_{5,0}, X_{5,1}, Y_{2,0}, Y_{2,1}, X_{1}, X_{3}, X_{5}, Y_{2}, Y_{4}, Y_{0}$ and $Z$ as follows. $X_{1,0}=[0,4], X_{1,1}=[5,8046090004], X_{5,0}=[0,2], X_{5,1}=[3,362], Y_{2,0}=$ $[0,59], Y_{2,1}=[60,299], X_{1}=X_{1,0} \cup X_{1,1}, X_{3}=Y_{4}=Y_{0}=[0,1], X_{5}=X_{5,0} \cup X_{5,1}, Y_{2}=$ $Y_{2,0} \cup Y_{2,1}$ and $Z=X_{1} \times X_{3} \times X_{5} \times Y_{2} \times Y_{4} \times Y_{0}$.

We denote by $*$ an arbitrary element of a factor of $Z$.

Definition 3.2. Let $\alpha_{0}, \alpha_{1}$ be injections from $\left\{\left(C_{0}, C_{1}\right) \in\left(\begin{array}{c}X_{1,0} \\ 3\end{array}\right)^{2} \mid \sharp C_{0} \cap C_{1}=1\right\}$ into $Y_{2,0}$ with disjoint images and let $\beta_{0,0}, \beta_{0,1}$, $\beta_{1,0}, \beta_{1,1}$ be injections from $\left\{\left(C_{0}, C_{1}\right) \in\left(\begin{array}{c}X_{1,0} \\ 3\end{array}\right)^{2} \mid \sharp C_{0} \cap C_{1}=2\right\}$ into $Y_{2,1}$ with disjoint images. If $a=\alpha_{i}\left(C, C^{\prime}\right)$ then we set $\bar{a}=\alpha_{i+1}\left(C, C^{\prime}\right)(i \in[0,1])$.

Definition 3.3. For $i, j \in[0,1]$ and $C \in\left(\begin{array}{c}X_{1,0} \\ 3\end{array}\right)$, we define $S_{i, j}^{\prime}(C), S_{i, j}^{\prime \prime}(C), S_{i}^{\prime}(C)$, $S_{i}^{\prime \prime}(C), S_{i}(C), S^{\prime}, S^{\prime \prime}$ as follows.

$$
\begin{aligned}
& S_{0, j}^{\prime}(C)=\left\{\alpha_{j}\left(C, C^{\prime}\right) \mid C^{\prime} \in\left(\begin{array}{c}
X_{1,0} \\
3
\end{array}\right), \sharp C \cap C^{\prime}=1\right\}, \\
& S_{1, j}^{\prime}(C)=\left\{\alpha_{j}\left(C^{\prime}, C\right) \mid C^{\prime} \in\left(\begin{array}{c}
X_{1,0} \\
3
\end{array}\right), \sharp C \cap C^{\prime}=1\right\}, \\
& S_{0, j}^{\prime \prime}(C)=\left\{\beta_{k, j}\left(C, C^{\prime}\right) \mid C^{\prime} \in\left(\begin{array}{c}
X_{1,0} \\
3
\end{array}\right), \sharp C \cap C^{\prime}=2, k \in[0,1]\right\}, \\
& S_{1, j}^{\prime \prime}(C)=\left\{\beta_{k, j}\left(C^{\prime}, C\right) \mid C^{\prime} \in\left(\begin{array}{c}
X_{1,0} \\
3
\end{array}\right), \sharp C \cap C^{\prime}=2, k \in[0,1]\right\}, \\
& S_{i}^{\prime}(C)=S_{i, 0}^{\prime}(C) \cup S_{i, 1}^{\prime}(C), S_{i}^{\prime \prime}(C)=S_{i, 0}^{\prime \prime}(C) \cup S_{i, 1}^{\prime \prime}(C), S_{i}(C)=S_{i}^{\prime}(C) \cup S_{i}^{\prime \prime}(C), \\
& S^{\prime}=\bigcup\left\{S_{0}^{\prime}(C) \mid C \in\left(\begin{array}{c}
X_{1,0} \\
3
\end{array}\right)\right\}=\bigcup\left\{S_{1}^{\prime}(C) \mid C \in\left(\begin{array}{c}
X_{1,0} \\
3
\end{array}\right)\right\}, \\
& S^{\prime \prime}=\bigcup\left\{S_{0}^{\prime \prime}(C) \mid C \in\left(\begin{array}{c}
X_{1,0} \\
3
\end{array}\right)\right\}=\bigcup\left\{S_{1}^{\prime \prime}(C) \mid C \in\left(\begin{array}{c}
X_{1,0} \\
3
\end{array}\right)\right\} .
\end{aligned}
$$

Definition 3.4. For $p \in X_{1,0}$ let $\gamma_{p}$ be a fixed bijection from $\left\{(c, i) \mid i \in Y_{4}, p \in C \in\right.$ $\left.\left(\begin{array}{c}X_{1,0} \\ 3\end{array}\right), c \in S_{i}(C)\right\}$ onto $X_{5,1}$, let $A_{p}=\{p, p+1, p+2\}, B_{p}=\{p, p+1, p+3\}$ and let $A_{p}(0)=B_{p}(0)=p, A_{p}(1)=B_{p}(1)=p+1, A_{p}(2)=p+2, B_{p}(2)=p+3$.

Definition 3.5. We define mappings $\rho$ from $Y_{2}$ into $X_{1,0} \cup\left(\begin{array}{c}X_{1,0} \\ 2\end{array}\right)$ and $\rho_{0}, \rho_{1}$ from $Y_{2,1}$ into $X_{1,0}$ as follows. For $i \in[0,1]$ and $C, C^{\prime} \in\left(\begin{array}{c}X_{1,0} \\ 3\end{array}\right)$ with $C \cap C^{\prime}=\{p\}$ let $\rho\left(\alpha_{i}\left(C, C^{\prime}\right)\right)=p$. For $i, j, k \in[0,1]$ and $C, C^{\prime} \in\left(\begin{array}{c}X_{1,0} \\ 3\end{array}\right)$ with $C \cap C^{\prime}=\left\{p_{0}, p_{1}\right\}$ where $p_{1} \in\left\{p_{0}+1, p_{0}+2\right\}$ let $\rho\left(\beta_{i, j}\left(C, C^{\prime}\right)\right)=\left\{p_{0}, p_{1}\right\}$ and let $\rho_{k}\left(\beta_{i, j}\left(C, C^{\prime}\right)\right)=p_{k}$. 
Definition 3.6. Let $i, j \in[0,1]$ and $p \in X_{1,0}$. We define $\lambda_{i} \in^{Y_{2,0}} X_{1,0}$ as follows.

$$
\begin{aligned}
\lambda_{i}\left(\alpha_{j}\left(A_{p}, A_{p+3}\right)\right) & =\lambda_{i}\left(\alpha_{j}\left(B_{p+4}, B_{p}\right)\right)=p+3-i, \\
\lambda_{i}\left(\alpha_{j}\left(B_{p}, B_{p+4}\right)\right) & =\lambda_{i}\left(\alpha_{j}\left(B_{p+2}, A_{p+4}\right)\right)=p+4-i, \\
\lambda_{i}\left(\alpha_{j}\left(A_{p+4}, B_{p+2}\right)\right) & =\lambda_{i}\left(\alpha_{j}\left(A_{p+3}, A_{p}\right)\right)=p+2+2 i .
\end{aligned}
$$

Definition 3.7. Let $i, j, k \in[0,1]$ and $C \in\left(\begin{array}{c}X_{1,0} \\ 3\end{array}\right)$. We define $\iota_{i, j} \in^{Y_{2}} X_{1,0}$ and $R_{i}(C, j) \subset S_{i}^{\prime \prime}(C)$ as follows. For $a \in Y_{2,0}$ if $a=\alpha_{j}\left(C_{0}, C_{1}\right)$ then $\iota_{i, j}(a) \in X_{1,0} \backslash$ $\left(C_{i} \cup\left\{\lambda_{i}(a)\right\}\right)$ and $\iota_{i, j+1}(a)=\lambda_{i}(a)$. For $b \in Y_{2,1}$ if $b=\beta_{j, k}\left(C_{0}, C_{1}\right)$ then $\iota_{i, j}(b) \in$ $X_{1,0} \backslash\left(C_{0} \cup C_{1}\right)$ and $\iota_{i, j+1}(b) \in C_{i+1} \backslash C_{i}$.

$$
R_{i}(C, j)=\left\{r \in S_{i}^{\prime \prime}(C) \mid \iota_{i, i+j}(r)=C(2)+1\right\} .
$$

Definition 3.8. Let $\mathcal{G}=\left\{g \in^{\left(Y_{4} \times Y_{0}\right)} Y_{2} \mid g(i, 0) \neq g(i, 1)\left(i \in Y_{4}\right)\right\}$ and let $h$ be a fixed bijection from $\mathcal{G}$ onto $X_{1,1}$. We define a subset $T_{-}$of $Z$ by

$$
T_{-}=\left\{(h(g), 0,0, g(i, j), i, j) \mid g \in \mathcal{G}, i \in Y_{4}, j \in Y_{0}\right\} .
$$

Definition 3.9. Let $i, j \in[0,1]$ and let $C \in\left(\begin{array}{c}X_{1,0} \\ 3\end{array}\right)$. For each $a \in S_{i, j}^{\prime}(C)$ and each $p \in C$, we define a subset $T_{p}^{0}\left(\gamma_{p}(a, i)\right)$ of $Z$ as follows.

$$
\begin{aligned}
& T_{p}^{1}\left(\gamma_{p}(a, i)\right)=\left\{\left(p, 0, \gamma_{p}(a, i), a, i, *\right)\right\}, \\
& T_{p}^{2}\left(\gamma_{p}(a, i)\right)=\left\{\left(p, 0, \gamma_{p}(a, i), r, i+1, k\right) \in Z \mid \iota_{i+1, k+1}(r)=p\right. \text { or } \\
& \left.r \in S^{\prime \prime} \text { with } \iota_{i+1, k}(r) \in C \backslash\{p\}, k \in[0,1]\right\}, \\
& T_{p}^{3}\left(\gamma_{p}(a, i)\right)=\left\{\left(p, 0, \gamma_{p}(a, i), r, i+1, *\right) \in Z \mid r \in \bigcup\left\{S_{i+1}^{\prime}\left(C^{\prime}\right) \mid p \in C^{\prime} \in\left(\begin{array}{c}
X_{1,0} \\
3
\end{array}\right)\right\}\right. \\
& \qquad\{\bar{a}\} \text { or } r \in \bigcup\left\{S_{i+1, k}^{\prime \prime}\left(C^{\prime}\right) \mid C^{\prime} \in\left(\begin{array}{c}
X_{1,0} \\
3
\end{array}\right) \text { is such that } C \cap C^{\prime}=\left\{p, p^{\prime}\right\}\right.
\end{aligned}
$$

Definition 3.10. Let $i, j, k \in[0,1]$ and let $C \in\left(\begin{array}{c}X_{1,0} \\ 3\end{array}\right)$. For each $b \in S_{i, j}^{\prime \prime}(C) \cap$ 
$R_{i}(C, k)$ and each $p \in C$, we define a subset $T_{p}^{0}\left(\gamma_{p}(b, i)\right)$ of $Z$ as follows.

$T_{p}^{1}\left(\gamma_{p}(b, i)\right)=\left\{\left(p, 0, \gamma_{p}(b, i), b, i, *\right)\right\}$,

$T_{p}^{2}\left(\gamma_{p}(b, i)\right)=\left\{\left(p, 0, \gamma_{p}(b, i), r, i+1, l\right) \in Z \mid \iota_{i+1, l}(r) \in C \backslash\{p\}\right.$ or $\left.\iota_{i+1, l+1}(r)=p\right\}$,

$T_{p}^{3}\left(\gamma_{p}(b, i)\right)=\left\{\left(p, 0, \gamma_{p}(b, i), r, i+1, *\right) \in Z \mid r \in S_{i+1}^{\prime}(C)\right.$ or

$$
r \in \bigcup\left\{S_{i+1, j+l}^{\prime \prime}\left(C^{\prime}\right) \mid C^{\prime} \in\left(\begin{array}{c}
X_{1,0} \\
3
\end{array}\right) \text { is such that } C \cap C^{\prime}=\left\{p, p^{\prime}\right\}\right.
$$

where $\left.p^{\prime} \in\{p+1+2 l, p+2+2 l\}, l \in[0,1]\right\} \backslash\{b\}$ or $r \in \bigcup\left\{S_{i+1}^{\prime}\left(C^{\prime}\right) \mid\right.$

$C^{\prime}$ is such that $C \cap C^{\prime}=\left\{p, p^{\prime}\right\}$ where $\left.\left.p^{\prime} \in\{p+1+2 j, p+2+2 j\}\right\}\right\}$

$T_{\rho_{j}(b)}^{4}\left(\gamma_{\rho_{j}(b)}(b, i)\right)=\left\{\left(\rho_{j}(b), 0, \gamma_{\rho_{j}(b)}(b, i), b, i+1, *\right)\right\}$,

$T_{p}^{4}\left(\gamma_{p}(b, i)\right)=\varnothing \quad\left(p \in C \backslash\left\{\rho_{j}(b)\right\}\right)$,

$T_{C(0)}^{5}\left(\gamma_{C(0)}(b, i)\right)=\left\{\left(C(0), 0, \gamma_{C(0)}(b, i), r, i+1, i\right) \in Z \mid r \in R_{i+1}(C, k), \rho(r) \neq \rho(b)\right\}$,

$T_{C(1)}^{5}\left(\gamma_{C(1)}(b, i)\right)=\left\{\left(C(1), 0, \gamma_{C(1)}(b, i), r, i+1, i\right) \in Z \mid r \in R_{i+1}(C, k)\right\}$,

$T_{C(2)}^{5}\left(\gamma_{C(2)}(b, i)\right)=\left\{\left(C(2), 0, \gamma_{C(2)}(b, i), r, i+1, i\right) \in Z \mid r \in R_{i+1}(C, k), \rho(r)=\rho(b)\right\}$,

$T_{C(0)}^{6}\left(\gamma_{C(0)}(b, i)\right)=\left\{\left(C(0), 0, \gamma_{C(0)}(b, i), r, i+1, i+1\right) \in Z \mid\right.$

$$
\left.r \in R_{i+1}(C, k), \rho(r)=\rho(b)\right\},
$$

$T_{C(1)}^{6}\left(\gamma_{C(1)}(b, i)\right)=\left\{\left(C(1), 0, \gamma_{C(1)}(b, i), r, i+1, i+1\right) \in Z \mid\right.$

$$
\left.r \in R_{i+1}(C, k), \rho(r) \neq \rho(b)\right\},
$$

$T_{C(2)}^{6}\left(\gamma_{C(2)}(b, i)\right)=\left\{\left(C(2), 0, \gamma_{C(2)}(b, i), r, i+1, i+1\right) \in Z \mid r \in R_{i+1}(C, k)\right\}$,

$T_{C(0)}^{7}\left(\gamma_{C(0)}(b, i)\right)=\left\{\left(C(0), 0, \gamma_{C(0)}(b, i), r, i+1, *\right) \in Z \mid r \in R_{i+1}(C, k+1)\right\}$,

$T_{C(1)}^{7}\left(\gamma_{C(1)}(b, i)\right)=\left\{\left(C(1), 0, \gamma_{C(1)}(b, i), r, i+1, k\right) \in Z \mid r \in R_{i+1}(C, k+1)\right\}$,

$T_{C(2)}^{7}\left(\gamma_{C(2)}(b, i)\right)=\left\{\left(C(2), 0, \gamma_{C(2)}(b, i), r, i+1, k+1\right) \in Z \mid r \in R_{i+1}(C, k+1)\right\}$,

$T_{p}^{0}\left(\gamma_{p}(b, i)\right)=\bigcup_{n \in[1,7]} T_{p}^{n}\left(\gamma_{p}(b, i)\right)$.

Definition 3.11. For each $p \in X_{1,0}$ and each $n \in[0,2]$, we define a subset $T_{p}^{0}(n)$ of $Z$ as follows.

$$
\begin{aligned}
& T_{p}^{1}(0)=\left\{(p, i+j, 0, r, i, j) \in Z \mid r \in\left\{\alpha_{j}\left(A_{p}, A_{p+3}\right), \alpha_{j}\left(B_{p+4}, B_{p}\right)\right\}, i, j \in[0,1]\right\}, \\
& T_{p}^{1}(1)=\left\{(p, i+j, 1, r, i, j) \in Z \mid r \in\left\{\alpha_{j}\left(B_{p}, B_{p+4}\right), \alpha_{j}\left(B_{p+2}, A_{p+4}\right)\right\}, i, j \in[0,1]\right\}, \\
& T_{p}^{1}(2)=\left\{(p, i+j, 2, r, i, j) \in Z \mid r \in\left\{\alpha_{j}\left(A_{p+4}, B_{p+2}\right), \alpha_{j}\left(A_{p+3}, A_{p}\right)\right\}, i, j \in[0,1]\right\}, \\
& T_{p}^{2}(0)=\left\{(p, *, 0, r, i, j) \in Z \mid \iota_{i, j}(r)=p+3-i \text { or } \iota_{i, j+1}(r)=p, i, j \in[0,1]\right\}, \\
& T_{p}^{2}(1)=\left\{(p, *, 1, r, i, j) \in Z \mid \iota_{i, j}(r)=p+4-i \text { or } \iota_{i, j+1}(r)=p, i, j \in[0,1]\right\}, \\
& T_{p}^{2}(2)=\left\{(p, *, 2, r, i, j) \in Z \mid \iota_{i, j}(r)=p+2+2 i \text { or } \iota_{i, j+1}(r)=p, i, j \in[0,1]\right\}, \\
& T_{p}^{0}(n)=T_{p}^{1}(n) \cup T_{p}^{2}(n) .
\end{aligned}
$$




\section{Definition 3.12.}

$$
\begin{aligned}
& T_{p}=\bigcup\left\{T_{p}^{0}\left(\gamma_{p}(c, i)\right) \mid p \in C \in\left(\begin{array}{c}
X_{1,0} \\
3
\end{array}\right), i \in Y_{4}, c \in S_{i}(C)\right\} \cup \underset{\substack{n \in[0,2] \\
\left(p \in X_{1,0}\right),}}{\bigcup} T_{p}^{0}(n) \\
& T=\bigcup_{p \in X_{1,0}} T_{p} \cup T_{-} .
\end{aligned}
$$

We define $F_{0} \in^{Z}[0,1]$ by $F_{0}^{-1}(1)=T$.

\section{Definition 3.13.}

$$
\begin{aligned}
& W_{p, q}=\left\{\left((r, i, j),\left(r^{\prime}, i+1, j^{\prime}\right)\right) \in\left(Y_{2} \times Y_{4} \times Y_{0}\right)^{2} \mid \text { there exist } k, k^{\prime} \in X_{3}\right. \\
& \text { such that } \left.(p, k, q, r, i, j),\left(p, k^{\prime}, q, r^{\prime}, i+1, j^{\prime}\right) \in T_{p}^{0}(q)\right\} \\
& \left(p \in X_{1,0}, q \in X_{5}\right), \\
& W_{p}=\bigcup_{q \in X_{5}} W_{p, q}\left(p \in X_{1,0}\right) .
\end{aligned}
$$

The following two lemmas are direct consequences of the definitions.

Lemma 3.1. Let $i, j \in[0,1]$ and $C \in\left(\begin{array}{c}X_{1,0} \\ 3\end{array}\right)$.

(1) $\left(p, 0, \gamma_{p}(c, i), c, i, *\right) \in T_{p}\left(\gamma_{p}(c, i)\right)$ for all $p \in C$ and $c \in S_{i}(C)$.

(2) If $(c, r, k) \in\left(S_{i}(C) \times Y_{2} \times Y_{0}\right) \backslash \bigcup_{a \in S_{i, j}^{\prime}(C)}\{(a, \bar{a}, j+1)\}$, then there exists $P \in\left(\begin{array}{c}C \\ 2\end{array}\right)$ such that for all $p \in P\left(p, 0, \gamma_{p}(c, i), r, i+1, k\right) \in T_{p}^{0}\left(\gamma_{p}(c, i)\right)$.

(3) If $a \in S_{i, j}^{\prime}(C)$ then there exists $q \in X_{5,0}$ such that $(\rho(a), i+j, q, a, i, *) \in T_{\rho(a)}^{0}(q)$ and $(\rho(a), i+j, q, \bar{a}, i+1, j+1) \in T_{\rho(a)}^{0}(q)$ and if $\iota_{i+1, j}(r)=\lambda_{i+1}(a)$ or $\iota_{i+1, j+1}(r)=\rho(a)$ then $(\rho(a), *, q, r, i+1, j) \in T_{\rho(a)}^{0}(q)$.

(4) If $a \in S_{i, j}^{\prime}(C)$ then $\left(\lambda_{i+1}(a), 0, \gamma_{\lambda_{i+1}(a)}(a, i), \bar{a}, i+1, j+1\right) \in T_{\lambda_{i+1}(a)}^{0}\left(\gamma_{\lambda_{i+1}(a)}(a, i)\right)$ and if $\iota_{i+1, j}(r) \neq \lambda_{i+1}(a)$ and $\iota_{i+1, j+1}(r) \neq \rho(a)$ then $\left(\lambda_{i+1}(a), 0, \gamma_{\lambda_{i+1}(a)}(a, i), r, i+1, j\right) \in T_{\lambda_{i+1}(a)}^{0}\left(\gamma_{\lambda_{i+1}(a)}(a, i)\right)$.

Proof. (1) Clear from the definition of $T_{p}^{1}\left(\gamma_{p}(c, i)\right)$.

(2) In case $c \in S_{i}^{\prime}(C)$ the claim follows from the definitions of $T_{p}^{2}\left(\gamma_{p}(c, i)\right)$ and $T_{p}^{3}\left(\gamma_{p}(c, i)\right)$, in case $(c, r) \in S_{i}^{\prime \prime}(C) \times\left(Y_{2} \backslash S_{i+1}^{\prime \prime}(C)\right)$ it follows from the definitions of $T_{p}^{2}\left(\gamma_{p}(c, i)\right), T_{p}^{3}\left(\gamma_{p}(c, i)\right)$ and $T_{\rho_{j}(C)}^{4}\left(\gamma_{\rho_{j}(C)}(c, i)\right)$, and in case $(c, r) \in S_{i}^{\prime \prime}(C) \times S_{i+1}^{\prime \prime}(C)$ it follows from the definition of $T_{C(n)}^{m}\left(\gamma_{C(n)}(b, i)\right)(m \in[5,7], n \in[0,2])$.

(3) Clear from Definition 3.11.

(4) Clear from $\iota_{i+1, j}(\bar{a})=\lambda_{i+1}(a)$ and the definitions of $T_{\lambda_{i+1}(a)}^{2}\left(\gamma_{\lambda_{i+1}(a)}(a, i)\right)$ and $T_{\lambda_{i+1}(a)}^{4}\left(\gamma_{\lambda_{i+1}(a)}(a, i)\right)$.

\section{Lemma 3.2.}


(1) Let $i, j, k, l \in[0,1]$ let $C, C^{\prime} \in\left(\begin{array}{c}X_{1,0} \\ 3\end{array}\right)$ with $C \cap C^{\prime}=\left\{p, p^{\prime}\right\}$ where $p \in\left\{p^{\prime}+1+\right.$ $\left.2 k, p^{\prime}+2+2 k\right\}$. Then for $b \in S_{i, j}^{\prime \prime}(C)$ and $b^{\prime} \in S_{i+1, j+k}^{\prime \prime}\left(C^{\prime}\right)$, if $\iota_{i, l}(b), \iota_{i+1, l+1}\left(b^{\prime}\right) \in$ $X \backslash\left(C \cup C^{\prime}\right)$, then $\left((b, i, l),\left(b^{\prime}, i+1, l+1\right)\right) \notin W_{p}$.

(2) Let $i, j, k \in[0,1]$ let $C, C^{\prime} \in\left(\begin{array}{c}X_{1,0} \\ 3\end{array}\right)$ with $\sharp C \cap C^{\prime}=2$ and let $b=\beta_{i, j}\left(C, C^{\prime}\right)$. Then $((b, k, i),(b, k+1, i)) \notin W_{\rho_{j+1}}(b)$.

(3) Let $i, j, k \in[0,1]$, let $C \in\left(\begin{array}{c}X_{1,0} \\ 3\end{array}\right)$ and let $b \in R_{k}(C, i)$ and $b^{\prime} \in R_{k+1}(C, j)$. If $i=j$, then there exists $l \in Y_{0}$ such that $\left((b, k, l),\left(b^{\prime}, k+1, l+1\right)\right) \notin W_{C(0)}$. If $i=j$ and $\rho(b)=\rho\left(b^{\prime}\right)$ or $i \neq j$, then there exists $l \in Y_{0}$ such that $\left((b, k, l),\left(b^{\prime}, k+1, l+1\right)\right) \notin$ $W_{C(1)}$. If $i=j$ and $\rho(b) \neq \rho\left(b^{\prime}\right)$ or $i \neq j$, then there exists $l \in Y_{0}$ such that $\left((b, k, l),\left(b^{\prime}, k+1, l+1\right)\right) \notin W_{C(2)}$.

(4) Let $i, j, k \in[0,1]$ and let $C, C^{\prime} \in\left(\begin{array}{c}X_{1,0} \\ 3\end{array}\right)$ with $C \cap C^{\prime}=\left\{p, p^{\prime}\right\}$ where $p \in\left\{p^{\prime}+\right.$ $\left.1+2 k, p^{\prime}+2+2 k\right\}$. Then for $a \in S_{i, j}^{\prime}(C)$ and $b \in S_{i+1, k}^{\prime \prime}\left(C^{\prime}\right)$, if $\lambda_{i}(a) \in C^{\prime}$ and $\iota_{i+1, j+1}(b) \in X_{1} \backslash\left(C \cup C^{\prime}\right)$, then $((a, i, j),(b, i+1, j+1)) \notin W_{p}$.

(5) Let $C, C^{\prime} \in\left(\begin{array}{c}X_{1,0} \\ 3\end{array}\right)$ with $C \cap C^{\prime}=\{p\}$ and let $a_{0}=\alpha_{0}\left(C, C^{\prime}\right)$ and $a_{1}=$ $\alpha_{1}\left(C, C^{\prime}\right)$. Then there exists $q \in X_{5,0}$ such that for all $i \in[0,1]$ and $q^{\prime} \in X_{5} \backslash$ $\{q\},\left(\left(a_{0}, i, 0\right),\left(a_{1}, i+1,1\right)\right) \in W_{p, q},\left(\left(a_{0}, i, 0\right),\left(a_{1}, i+1,1\right)\right) \notin W_{p, q^{\prime}}$ and $\left(p, i, q, a_{0}, i+\right.$ $1,0) \notin T_{p}$.

Proof. (1) Clear from $\left(p, 0, \gamma_{p}(b, i), b^{\prime}, i+1, l+1\right) \notin T_{p}^{n}\left(\gamma_{p}(b, i)\right)$ and $\left(p, 0, \gamma_{p}\left(b^{\prime}, i+\right.\right.$ $1), b, i, l) \notin T_{p}^{n}\left(\gamma_{p}\left(b^{\prime}, i+1\right)\right)(n \in[2,3])$.

(2) Clear from $\left(p, 0, \gamma_{p}(b, l), b, l+1, i\right) \notin T_{p}^{2}\left(\gamma_{p}(b, l)\right)(l \in[0,1])$.

(3) If $i \neq j$, since there do not exist $l, l^{\prime} \in[0,1]$ and $n \in[0,2]$ such that $(C(1), l, n, b$, $k, i),\left(C(1), l^{\prime}, n, b^{\prime}, k+1, j\right) \in T_{C(1)}^{0}(n)$ and since $\left(C(1), 0, \gamma_{C(1)}(b, k), b^{\prime}, k+1, j\right) \notin T_{C(1)}^{0}$ $\left(\gamma_{C(1)}(b, k)\right)$ and $\left(C(1), 0, \gamma_{C(1)}\left(b^{\prime}, k+1\right), b, k, i\right) \notin T_{C(1)}^{0}\left(\gamma_{C(1)}\left(b^{\prime}, k+1\right)\right)$, it follows that $\left((b, k, i),\left(b^{\prime}, k+1, j\right)\right) \notin W_{C(1)}$. Similarly we have $\left((b, k, j),\left(b^{\prime}, k+1, i\right)\right) \notin W_{C(2)}$. Similarly if $i=j$ and $\rho(b)=\rho\left(b^{\prime}\right)$ we have $\left((b, k, k+1),\left(b^{\prime}, k+1, k\right)\right) \notin W_{C(0)}$ and $\left((b, k, k),\left(b^{\prime}, k+1, k+1\right)\right) \notin W_{C(1)}$, if $i=j$ and $\rho(b) \neq \rho\left(b^{\prime}\right)$ we have $\left((b, k, k),\left(b^{\prime}, k+\right.\right.$ $1, k+1)) \notin W_{C(0)}$ and $\left((b, k, k+1),\left(b^{\prime}, k+1, k\right)\right) \notin W_{C(2)}$.

(4) Clear from $\left(p, 0, \gamma_{p}(b, i+1), a, i, j\right) \notin T_{p}^{n}\left(\gamma_{p}(b, i+1)\right)$ and $\left(p, 0, \gamma_{p}(a, i), b, i+\right.$ $1, j+1) \notin T_{p}^{n}\left(\gamma_{p}(a, i)\right)(n \in[2,3])$.

(5) If $\left(\left(a_{0}, i, 0\right),\left(a_{1}, i+1,1\right)\right) \in W_{p, q}$, then $q \in X_{5,0}$. From Definition 3.11 it follows that there exists a unique $q \in X_{5,0}$ such that $\left(\left(a_{0}, i, 0\right),\left(a_{1}, i+1,1\right)\right) \in W_{p, q}$, and for this $\mathrm{q},\left(p, i, q, a_{0}, i+1,0\right) \notin T_{p}$.

As an immediate consequence of Lemma 3.1, we can prove $\mu\left(F_{0}\right)=1$. Let $r, r^{\prime} \in Y_{2}$ and let $i \in Y_{4}$. Let $C \in\left(\begin{array}{c}X_{1,0} \\ 3\end{array}\right)$ and let $c \in S_{i}(C)$. Lemma 3.1 implies that there exist $p \in C, k \in X_{3}, q \in X_{5}$ such that $(p, k, q, c, i, *),(p, k, q, r, i+1,0),\left(p, k, q, r^{\prime}, i+1,1\right) \in$ 
$T_{p}^{0}(q)$, and so for $g \in^{\left(Y_{4} \times Y_{0}\right)} Y_{2} \backslash \mathcal{G}$, there exist $p \in C, k \in X_{3}, q \in X_{5}$ such that for all $i \in Y_{4}$ and $j \in Y_{0}(p, k, q, g(i, j), i, j) \in T_{p}^{0}(q)$. If $g \in \mathcal{G}$ then $(h(g), 0,0, g(i, j), i, j) \in T_{-}$ for all $i \in Y_{4}$ and $j \in Y_{0}$. Therefore, for all $g \in^{\left(Y_{4} \times Y_{0}\right)} Y_{2}$, there exist $p \in X_{1}, k \in X_{3}$ and $q \in X_{5}$ such that $(p, k, q, g(i, j), i, j) \in T$ for all $i \in Y_{4}$ and $j \in Y_{0}$. Hence $\mu\left(F_{0}\right)=1$.

3.2. Proof of $\tau\left(F_{0}\right)=0$

Lemma 3.3. Let $f \in \in^{\left(Y_{2} \times Y_{4}\right)} X_{1}$ and $i, j \in[0,1]$.

(1) For all $C \in\left(\begin{array}{c}X_{1,0} \\ 3\end{array}\right)$ and $c \in S_{i}(C)$, if $f(c, i) \notin C$, then $\tau^{f}\left(F_{0}\right)=0$.

(2) For all $c_{0}, c_{1} \in Y_{2}$ and $p \in X_{1,0}$, if $\left(\left(c_{i}, i, j\right),\left(c_{i+1}, i+1, j+1\right)\right) \notin W_{p}$ and $f\left(c_{0}, 0\right)=$ $f\left(c_{1}, 1\right)=p$, then $\tau^{f}\left(F_{0}\right)=0$.

(3) For all $c \in Y_{2}$ and $p \in X_{1,0}$, if $((c, i, j),(c, i+1, j)) \notin W_{p}$ and $f(c, 0)=f(c, 1)=p$, then $\tau^{f}\left(F_{0}\right)=0$.

Proof. Let $f_{3} \in \in^{\left(X_{1} \times X_{5} \times Y_{2} \times Y_{0}\right)} X_{3}, f_{5} \in^{X_{1}} X_{5}, g_{2} \in^{Y_{0}} Y_{2}, g_{0} \in \in^{Y_{4}} Y_{2}$ and let $x_{1}=$ $f_{1}\left(y_{2}, y_{4}\right), x_{3}=f_{3}\left(x_{1}, x_{5}, y_{2}, y_{0}\right), x_{5}=f_{5}\left(x_{1}\right), y_{2}=g_{2}\left(y_{0}\right)$ and $y_{0}=g_{0}\left(y_{4}\right)$.

(1) If $p=f(c, i) \notin C$, then there exists $k \in Y_{0}$ such that $(p, *, *, c, i, k) \notin T$. So if we let $y_{4}=i$ and $g_{2}, g_{0}$ be such that $g_{2}(k)=c, g_{0}(i)=k$, and set $q=f_{5}(p)$ and $l=f_{3}(p, q, c, k)$, then

$$
\begin{aligned}
\left(x_{1}, x_{3}, x_{5}, y_{2}, y_{4}, y_{0}\right) & =\left(f\left(y_{2}, y_{4}\right), f_{3}\left(x_{1}, x_{5}, y_{2}, y_{0}\right), f_{5}\left(x_{1}\right), g_{2}\left(y_{0}\right), y_{4}, g_{0}\left(y_{4}\right)\right) \\
& =(p, l, q, c, i, k) \notin T .
\end{aligned}
$$

Hence $\tau^{f}\left(F_{0}\right)=0$.

(2) Let $g_{2}, g_{0}$ be such that $g_{2}(j)=c_{i}, g_{2}(j+1)=c_{i+1}, g_{0}(i)=j, g_{0}(i+1)=$ $j+1$, and set $q=f_{5}(p), k_{i}=f_{3}\left(p, q, c_{i}, j\right)$ and $k_{i+1}=f_{3}\left(p, q, c_{i+1}, j+1\right)$. The condition $\left(\left(c_{i}, i, j\right),\left(c_{i+1}, i+1, j+1\right)\right) \notin W_{p}$ ensures that there exists $l \in Y_{4}$ such that $\left(p, k_{l}, q, c_{l}, l, i+j+l\right) \notin T_{p}$. So if we let $y_{4}=l$, then

$$
\left(f\left(y_{2}, y_{4}\right), f_{3}\left(x_{1}, x_{5}, y_{2}, y_{0}\right), f_{5}\left(x_{1}\right), g_{2}\left(y_{0}\right), y_{4}, g_{0}\left(y_{4}\right)\right)=\left(p, k_{l}, q, c_{l}, l, i+j+l\right) \notin T_{p} .
$$

Hence $\tau^{f}\left(F_{0}\right)=0$.

(3) Let $g_{2}, g_{0}$ be such that $g_{2}(j)=c, g_{0}(0)=g_{0}(1)=j$, and set $q=f_{5}(p)$ and $k=f_{3}(p, q, c, j)$. The condition $((c, i, j),(c, i+1, j)) \notin W_{p}$ ensures that there exists $l \in Y_{4}$ such that $(p, k, q, c, l, j) \notin T_{p}$. So if we let $y_{4}=l$, then

$$
\left(f\left(y_{2}, y_{4}\right), f_{3}\left(x_{1}, x_{5}, y_{2}, y_{0}\right), f_{5}\left(x_{1}\right), g_{2}\left(y_{0}\right), y_{4}, g_{0}\left(y_{4}\right)\right)=(p, k, q, c, l, j) \notin T_{p} .
$$

Hence $\tau^{f}\left(F_{0}\right)=0$.

Lemma 3.4. Let $C \in\left(\begin{array}{c}X_{1,0} \\ 3\end{array}\right)$ and $f \in^{\left(Y_{2} \times Y_{4}\right)} X_{1}$. If $\tau^{f}\left(F_{0}\right)=1$ then

$$
f\left(S_{i+1}^{\prime \prime}(C) \times\{i+1\}\right) \not \subset f\left(S_{i}^{\prime \prime}(C) \times\{i\}\right) \subset C \quad(i \in[0,1])
$$

and hence

$$
\sharp f\left(S_{i}^{\prime \prime}(C) \times\{i\}\right) \leqslant 2(i \in[0,1]) \text { and } \sharp \bigcap_{i \in[0,1]} f\left(S_{i}^{\prime \prime}(C) \times\{i\}\right) \leqslant 1 .
$$


Proof. Let $C \in\left(\begin{array}{c}X_{1,0} \\ 3\end{array}\right), f \in \in^{\left(Y_{2} \times Y_{4}\right)} X_{1}$ and let $\tau^{f}\left(F_{0}\right)=1$. For each $i \in[0,1]$, let $Q_{i}=\left\{r_{i, 0}, r_{i, 1}, r_{i, 2}, r_{i, 3}, r_{i, 4}, r_{i, 5}\right\} \subset S_{i}^{\prime \prime}(C)$ satisfies the following two conditions.

- $r_{i, 2 m} \in R_{i}(C, 0), r_{i, 2 m+1} \in R_{i}(C, 1) \quad(m \in[0,2])$.

- $\rho\left(r_{i, m}\right) \neq \rho\left(r_{i, n}\right) \quad(m, n \in[0,5], m \equiv n(\bmod 2), m \neq n)$.

Then, since $\tau^{f}\left(F_{0}\right)=1$, it follows from Lemma 3.3(1) that $f\left(Q_{i} \times\{i\}\right) \subset C(i \in[0,1])$ and from Lemma 3.2(3), Lemma 3.3(2) that

- if $f\left(r_{0, m}, 0\right)=f\left(r_{1, n}, 1\right)=C(0)$ then $m \not \equiv n(\bmod 2)$,

- if $f\left(r_{0, m}, 0\right)=f\left(r_{1, n}, 1\right)=C(1)$ then $m \equiv n(\bmod 2)$ and $\rho\left(r_{0, m}\right) \neq \rho\left(r_{1, n}\right)$,

- if $f\left(r_{0, m}, 0\right)=f\left(r_{1, n}, 1\right)=C(2)$ then $m \equiv n(\bmod 2)$ and $\rho\left(r_{0, m}\right)=\rho\left(r_{1, n}\right)$ $(m, n \in[0,5])$.

Therefore

$$
\text { if } C(m) \in f\left(Q_{i} \times\{i\}\right) \text {, then } \sharp\left\{r \in Q_{i+1} \mid f(r, i+1)=C(m)\right\} \leqslant 3-m
$$

$$
(i \in[0,1], m \in[0,2]) .
$$

Hence, if $\sharp f\left(Q_{i} \times\{i\}\right)=3$, then $\sharp f\left(Q_{i+1} \times\{i+1\}\right)=3$ and so

$$
\sharp\left\{r \in Q_{0} \mid f(r, 0)=C(1)\right\}=\sharp\left\{r \in Q_{1} \mid f(r, 1)=C(1)\right\}=2 .
$$

But this contradicts (1). Therefore $\sharp f\left(Q_{i} \times\{i\}\right) \leqslant 2$. Then it follows from (2) that

$$
f\left(Q_{i+1} \times\{i+1\}\right) \not \subset f\left(Q_{i} \times\{i\}\right) \quad(i \in[0,1]) .
$$

Since (3) holds for any $Q_{0}, Q_{1}$ satisfying the above conditions, we have

$$
f\left(S_{i+1}^{\prime \prime}(C) \times\{i+1\}\right) \not \subset f\left(S_{i}^{\prime \prime}(C) \times\{i\}\right) \subset C \quad(i \in[0,1])
$$

and hence

$$
\sharp f\left(S_{i}^{\prime \prime}(C) \times\{i\}\right) \leqslant 2 \quad(i \in[0,1]) \text { and } \sharp \bigcap_{i \in[0,1]} f\left(S_{i}^{\prime \prime}(C) \times\{i\}\right) \leqslant 1 .
$$

Lemma 3.5. Let $p \in C \in\left(\begin{array}{c}X_{1,0} \\ 3\end{array}\right), i \in[0,1]$ and $f \in \in^{\left(Y_{2} \times Y_{4}\right)} X_{1}$. If $\tau^{f}\left(F_{0}\right)=1$ and $\sharp\left\{r \in S_{i}^{\prime \prime}(C) \mid f(r, i)=p\right\}>12$, then

(1) $\left\{r \in S_{i+1}^{\prime \prime}(C) \mid f(r, i+1)=p\right\}=\varnothing$,

(2) $\sharp\left\{r \in S_{i+1}^{\prime \prime}\left(C^{\prime}\right) \mid f(r, i+1)=p\right\} \leqslant 6 \quad\left(C^{\prime} \in\left(\begin{array}{c}X_{1,0} \\ 3\end{array}\right), \sharp C \cap C^{\prime}=2\right)$. 
Proof. (1) The result follows immediately from Lemma 3.2(3) and Lemma 3.3(2).

(2) Let $l \in[0,1]$ and let $C^{\prime} \in\left(\begin{array}{c}X_{1,0} \\ 3\end{array}\right)$ with $C \cap C^{\prime}=\left\{p, p^{\prime}\right\}$ where $p^{\prime} \in$ $\{p+1+2 l, p+2+2 l\}$. The condition $\sharp\left\{r \in S_{i}^{\prime \prime}(C) \mid f(r, i)=p\right\}>12$ ensures that there exist $j, k \in[0,1], r_{0} \in S_{i, 0}^{\prime \prime}(C), r_{1} \in S_{i, 1}^{\prime \prime}(C)$ and $r_{2} \in S_{i, k}^{\prime \prime}(C)$ such that $\iota_{i, j}\left(r_{0}\right), \iota_{i, j}\left(r_{1}\right), \iota_{i, j+1}\left(r_{2}\right) \in X_{1,0} \backslash\left(C \cup C^{\prime}\right)$ and $f\left(r_{0}, i\right)=f\left(r_{1}, i\right)=f\left(r_{2}, i\right)=p$. Then, since $\tau^{f}\left(F_{0}\right)=1$, it follows from Lemma 3.2(1) and Lemma 3.3(2) that

$$
\left\{r \in S_{i+1}^{\prime \prime}\left(C^{\prime}\right) \mid f(r, i+1)=p\right\} \subset\left\{r \in S_{i+1, k+l}^{\prime \prime}\left(C^{\prime}\right) \mid \iota_{i+1, j}(r) \in X_{1,0} \backslash\left(C \cup C^{\prime}\right)\right\} .
$$

Hence $\sharp\left\{r \in S_{i+1}^{\prime \prime}\left(C^{\prime}\right) \mid f(r, i+1)=p\right\} \leqslant 6$.

Lemma 3.6. Let $p \in C \in\left(\begin{array}{c}X_{1,0} \\ 3\end{array}\right), i \in[0,1]$ and $f \in^{\left(Y_{2} \times Y_{4}\right)} X_{1}$. If $\tau^{f}\left(F_{0}\right)=1$ and $\left\{r \in S_{i}^{\prime \prime}(C) \mid f(r, i)=p\right\}=S_{i}^{\prime \prime}(C)$ then

$$
\left\{r \in S_{i+1}^{\prime \prime}\left(C^{\prime}\right) \mid f(r, i+1)=p\right\}=\varnothing \quad\left(C^{\prime} \in\left(\begin{array}{c}
X_{1,0} \\
3
\end{array}\right), \sharp C \cap C^{\prime} \geqslant 2\right) .
$$

Proof. Let $C^{\prime} \in\left(\begin{array}{c}X_{1,0} \\ 3\end{array}\right)$. In case $\sharp C \cap C^{\prime}=3$, the result follows from Lemma 3.5(1). In case $\sharp C \cap C^{\prime}=2$, let $j \in[0,1]$ and let $C \cap C^{\prime}=\left\{p, p^{\prime}\right\}$ where $p \in\left\{p^{\prime}+1+2 j, p^{\prime}+2+2 j\right\}$. Assume to the contrary that $\left\{r \in S_{i+1}^{\prime \prime}\left(C^{\prime}\right) \mid f(r, i+1)=p\right\} \neq \varnothing$. Let $k, l \in[0,1]$ and let $r^{\prime} \in S_{i+1, k}^{\prime \prime}\left(C^{\prime}\right)$ be such that $f\left(r^{\prime}, i+1\right)=p$ and $\iota_{i+1, l}\left(r^{\prime}\right) \in X_{1,0} \backslash\left(C \cup C^{\prime}\right)$. Then if $r \in S_{i, k+j}^{\prime \prime}(C)$ and $\iota_{i, l+1}(r) \in X \backslash\left(C \cup C^{\prime}\right)$ it follows from Lemma 3.2(1) that $\left((r, i, l+1),\left(r^{\prime}, i+1, l\right)\right) \notin W_{p}$. So by Lemma $3.3(2)$, since $f(r, i)=f\left(r^{\prime}, i+1\right)=p$, we get $\tau^{f}\left(F_{0}\right)=0$, contradicting $\tau^{f}\left(F_{0}\right)=1$.

Lemma 3.7. Let $p \in C \in\left(\begin{array}{c}X_{1,0} \\ 3\end{array}\right), i \in[0,1]$ and $f \in \in^{\left(Y_{2} \times Y_{4}\right)} X_{1}$. If $\tau^{f}\left(F_{0}\right)=1$ and $\sharp\left\{r \in S_{i}^{\prime \prime}(C) \mid f(r, i)=p\right\}=12$, then $\left\{r \in S_{i+1}^{\prime \prime}(C) \mid f(r, i+1)=p\right\}=\varnothing$ or $\sharp\left\{r \in S_{i+1}^{\prime \prime}\left(C^{\prime}\right) \mid f(r, i+1)=p\right\}<12 \quad\left(C^{\prime} \in\left(\begin{array}{c}X_{1,0} \\ 3\end{array}\right), \sharp C \cap C^{\prime}=2\right)$.

Proof. ¿From $\sharp\left\{r \in S_{i}^{\prime \prime}(C) \mid f(r, i)=p\right\}=12$, we have

$$
\left\{r \in S_{i}^{\prime \prime}(C) \mid f(r, i)=p\right\} \cap R_{i}(C, j) \neq \varnothing(j \in[0,1])
$$

or

$$
\left\{r \in S_{i}^{\prime \prime}(C) \mid f(r, i)=p\right\}=R_{i}\left(C, i_{0}\right) \text { for some } i_{0} \in[0,1] \text {. }
$$

In the first case it follows immediately from Lemma 3.2(3) and Lemma 3.3(2) that $\left\{r \in S_{i+1}^{\prime \prime}(C) \mid f(r, i+1)=p\right\}=\varnothing$.

In the second case, $\left\{r \in S_{i}^{\prime \prime}(C) \mid f(r, i)=p\right\} \cap S_{i, j}^{\prime \prime}(C) \neq \varnothing(j \in[0,1])$ and for $C^{\prime} \in\left(\begin{array}{c}X_{1,0} \\ 3\end{array}\right)$ with $\sharp C \cap C^{\prime}=2$, there exists $k \in[0,1]$ such that

$$
\left\{r \in S_{i}^{\prime \prime}(C) \mid f(r, i)=p\right\}=\left\{r \in S_{i}^{\prime \prime}(C) \mid \iota_{i, k}(r) \in X_{1,0} \backslash\left(C \cup C^{\prime}\right)\right\} .
$$


Assume to obtain a contradiction that $\sharp\left\{r \in S_{i+1}^{\prime \prime}\left(C^{\prime}\right) \mid f(r, i+1)=p\right\} \geqslant 12$. Then

$$
\left\{r \in S_{i+1}^{\prime \prime}\left(C^{\prime}\right) \mid f(r, i+1)=p\right\} \cap\left\{r \in S_{i+1}^{\prime \prime}\left(C^{\prime}\right) \mid \iota_{i+1, k+1}(r) \in X_{1,0} \backslash\left(C \cup C^{\prime}\right)\right\} \neq \varnothing
$$

or

$$
\left\{r \in S_{i+1}^{\prime \prime}\left(C^{\prime}\right) \mid f(r, i+1)=p\right\}=\left\{r \in S_{i+1}^{\prime \prime}\left(C^{\prime}\right) \mid \iota_{i+1, k}(r) \in X_{1,0} \backslash\left(C \cup C^{\prime}\right)\right\} .
$$

In the former case it follows from Lemma 3.2(1) and Lemma 3.3(2) that $\tau^{f}\left(F_{0}\right)=$ 0. In the latter case if we let $C=C_{i}$ and $C^{\prime}=C_{i+1}$, then $f\left(\beta_{k, j}\left(C_{0}, C_{1}\right), 0\right)=$ $f\left(\beta_{k, j}\left(C_{0}, C_{1}\right), 1\right)=p(j \in[0,1])$. Then it follows from Lemma 3.2(2) and Lemma $3.3(3)$ that $\tau^{f}\left(F_{0}\right)=0$. Since $\tau^{f}\left(F_{0}\right)=1$, we obtain a contradiction in both cases.

Lemma 3.8. Let $C_{0}, C_{1} \in\left(\begin{array}{c}X_{1,0} \\ 3\end{array}\right)$ and $f \in\left(^{\left(Y_{2} \times Y_{4}\right)} X_{1}\right.$. If $\tau^{f}\left(F_{0}\right)=1$ then

$$
\sharp \bigcap_{i \in[0,1]} f\left(S_{i}^{\prime \prime}\left(C_{i}\right) \times\{i\}\right) \leqslant 1
$$

Proof. If $\sharp C_{0} \cap C_{1}=1$ or $C_{0}=C_{1}$, the result is clear from Lemma 3.3(1) or Lemma 3.4. Let $C_{0} \cap C_{1}=\left\{p_{0}, p_{1}\right\}$ where $p_{1} \in\left\{p_{0}+1, p_{0}+2\right\}$. Since $\tau^{f}\left(F_{0}\right)=1$, Lemma 3.4 implies that $f\left(S_{i}^{\prime \prime}\left(C_{i}\right) \times\{i\}\right) \subset\left(\begin{array}{c}C_{i} \\ 2\end{array}\right)(i \in[0,1])$. We assume that $\bigcap_{i \in[0,1]} f\left(S_{i}^{\prime \prime}\left(C_{i}\right) \times\{i\}\right)=$ $\left\{p_{0}, p_{1}\right\}$ and derive a contradiction to the assumption $\tau^{f}\left(F_{0}\right)=1$. There are two cases. Either there exist $i, j \in[0,1]$ such that

$$
\left\{f(r, i) \mid r \in S_{i}^{\prime \prime}\left(C_{i}\right), \iota_{i, j}(r) \in X_{1,0} \backslash\left(C_{0}, C_{1}\right)\right\}=\left\{p_{0}, p_{1}\right\}
$$

or

$$
\sharp\left\{f(r, i) \mid r \in S_{i}^{\prime \prime}\left(C_{i}\right), \iota_{i, j}(r) \in X_{1,0} \backslash\left(C_{0}, C_{1}\right)\right\}=1(i, j \in[0,1]) .
$$

In the former case there exist $k \in[0,1], r_{0} \in S_{i, k}^{\prime \prime}\left(C_{i}\right), r_{1} \in S_{i, k+1}^{\prime \prime}\left(C_{i}\right)$ such that $\iota_{i, j}\left(r_{l}\right) \in X_{1,0} \backslash\left(C_{0} \cup C_{1}\right)$ and $f\left(r_{l}, i\right)=p_{l}(l \in[0,1])$. Let $r \in S_{i+1, k+1}^{\prime \prime}\left(C_{i+1}\right)$ with $\iota_{i+1, j+1}(r) \in X_{1,0} \backslash\left(C_{0} \cup C_{1}\right)$. Then by Lemma 3.2(1) we get $\left(\left(r_{l}, i, j\right),(r, i+1, j+1)\right) \notin$ $W_{p_{l}}(l \in[0,1])$. Hence, if $f(r, i+1) \in\left\{p_{0}, p_{1}\right\}$, it follows from Lemma 3.3(2) that $\tau^{f}\left(F_{0}\right)=0$.

In the latter case, for each $i \in[0,1]$, let $k_{i} \in[0,1]$ be such that

$$
\left\{f(r, i) \mid r \in S_{i}^{\prime \prime}\left(C_{i}\right), \iota_{i, 0}(r) \in X_{1,0} \backslash\left(C_{0} \cup C_{1}\right)\right\}=\left\{p_{k_{i}}\right\} .
$$

Set $k=k_{0}$. If $k \neq k_{1}$ then, since $\bigcap_{i \in[0,1]} f\left(S_{i}^{\prime \prime}\left(C_{i}\right) \times\{i\}\right)=\left\{p_{0}, p_{1}\right\}$, we have

$$
\begin{aligned}
& \left\{f(r, 0) \mid r \in S_{0}^{\prime \prime}\left(C_{0}\right), \iota_{0,0}(r) \in X_{1,0} \backslash\left(C_{0} \cup C_{1}\right)\right\} \\
= & \left\{f(r, 1) \mid r \in S_{1}^{\prime \prime}\left(C_{1}\right), \iota_{1,1}(r) \in X_{1,0} \backslash\left(C_{0} \cup C_{1}\right)\right\}=\left\{p_{k}\right\} .
\end{aligned}
$$


Let $r_{0} \in S_{0,0}^{\prime \prime}\left(C_{0}\right)$ with $\iota_{0,0}\left(r_{0}\right) \in X_{1,0} \backslash\left(C_{0} \cup C_{1}\right)$ and let $r_{1} \in S_{1, k+1}^{\prime \prime}\left(C_{1}\right)$ with $\iota_{1,1}\left(r_{1}\right) \in$ $X_{1,0} \backslash\left(C_{0} \cup C_{1}\right)$. Then it follows from Lemma 3.2(1) that $\left(\left(r_{0}, 0,0\right),\left(r_{1}, 1,1\right)\right) \notin W_{p_{k}}$ and so by Lemma $3.3(2), \tau^{f}\left(F_{0}\right)=0$. If $k=k_{1}$ then

$$
\begin{aligned}
& \left\{f(r, 0) \mid r \in S_{0}^{\prime \prime}\left(C_{0}\right), \iota_{0,0}(r) \in X_{1,0} \backslash\left(C_{0} \cup C_{1}\right)\right\} \\
= & \left\{f(r, 1) \mid r \in S_{1}^{\prime \prime}\left(C_{1}\right), \iota_{1,0}(r) \in X_{1,0} \backslash\left(C_{0} \cup C_{1}\right)\right\}=\left\{p_{k}\right\} .
\end{aligned}
$$

Then if we let $b=\beta_{0, k+1}\left(C_{0}, C_{1}\right)$ then $f(b, 0)=f(b, 1)=p_{k}$ and $\rho_{k}(b)=p_{k}$. Hence, by Lemma 3.2(2) and Lemma 3.3(3), $\tau^{f}\left(F_{0}\right)=0$.

Lemma 3.9. Let $C_{0}, C_{1} \in\left(\begin{array}{c}X_{1,0} \\ 3\end{array}\right)$ with $C_{0} \cap C_{1}=\{p\}$ and $f \in^{\left(Y_{2} \times Y_{4}\right)} X_{1}$. If $f\left(\alpha_{i}\left(C_{0}, C_{1}\right), j\right)=p(i, j \in[0,1])$ then $\tau^{f}\left(F_{0}\right)=0$.

Proof. Let $f_{3} \in\left(^{\left(X_{1} \times X_{5} \times Y_{2} \times Y_{0}\right)} X_{3}, f_{5} \in X^{X_{1}} X_{3}, g_{2} \in \in^{Y_{0}} Y_{2}\right.$ and $g_{0} \in \mathcal{Y}^{Y_{4}} Y_{0}$. Let $x_{1}=$ $f\left(y_{2}, y_{4}\right), x_{3}=f_{3}\left(x_{1}, x_{5}, y_{2}, y_{0}\right), x_{5}=f_{5}\left(x_{1}\right), y_{2}=g_{2}\left(y_{0}\right)$ and $y_{0}=g_{0}\left(y_{4}\right)$. Set $a_{i}=\alpha_{i}\left(C_{0}, C_{1}\right)(i \in[0,1])$. By Lemma 3.2(5), there exists a unique $q \in X_{5}$ such that $\left(\left(a_{0}, i, 0\right),\left(a_{1}, i+1,1\right)\right) \in W_{p, q}(i \in[0,1])$. Let $g_{2}(0)=a_{0}$ and $g_{2}(1)=a_{1}$. Set $k=f_{3}\left(p, q, a_{0}, 0\right)$ and let $g_{0}(k)=1$ and $g_{0}(k+1)=0$.

In case $f_{5}(p)=q$, let $y_{4}=k+1$, then by Lemma $3.2(5)$,

$$
\begin{aligned}
\left(x_{1}, x_{3}, x_{5}, y_{2}, y_{4}, y_{0}\right) & =\left(f\left(y_{2}, y_{4}\right), f_{3}\left(x_{1}, x_{5}, y_{2}, y_{0}\right), f_{5}\left(x_{1}\right), g_{2}\left(y_{0}\right), y_{4}, g_{0}\left(y_{4}\right)\right) \\
& =\left(p, k, q, a_{0}, k+1,0\right) \notin T_{p} .
\end{aligned}
$$

In case $f_{5}(p)=q^{\prime} \neq q$, if $\left(p, *, q^{\prime}, a_{0}, k+1,0\right) \notin T_{p}$ then let $y_{4}=k+1$ and set $l=f_{3}\left(p, q^{\prime}, a_{0}, 0\right)$. Then

$$
\left(f\left(y_{2}, y_{4}\right), f_{3}\left(x_{1}, x_{5}, y_{2}, y_{0}\right), f_{5}\left(x_{1}\right), g_{2}\left(y_{0}\right), y_{4}, g_{0}\left(y_{4}\right)\right)=\left(p, l, q^{\prime}, a_{0}, k+1,0\right) \notin T_{p} .
$$

If there exists $j \in[0,1]$ such that $\left(p, j, q^{\prime}, a_{0}, k+1,0\right) \in T_{p}$, then since $\left(\left(a_{0}, k+\right.\right.$ $\left.1,0),\left(a_{1}, k, 1\right)\right) \notin W_{p, q^{\prime}}$, if we let $y_{4}=k$ and set $l=f_{3}\left(p, q^{\prime}, a_{1}, 1\right)$ we have

$$
\left(f\left(y_{2}, y_{4}\right), f_{3}\left(x_{1}, x_{5}, y_{2}, y_{0}\right), f_{5}\left(x_{1}\right), g_{2}\left(y_{0}\right), y_{4}, g_{0}\left(y_{4}\right)\right)=\left(p, l, q^{\prime}, a_{1}, k, 1\right) \notin T_{p} .
$$

Therefore $\tau^{f}\left(F_{0}\right)=0$.

Proposition 3.1. Let $s>0$. For each $k \in[0,1]$, let $M_{k}$ be a nonnegative $4 \times 4$ matrix such that $M_{k}(m, m)=0$ and $\sum_{n=0}^{3} M_{k}(m, n)=2 s$ for all $m \in[0,3]$. Furthermore we assume the following properties.

(i) For all $k \in[0,1]$ and $m, m^{\prime}, n \in[0,3]$, if $M_{k}(m, n)>s$ then $M_{k+1}(m, n)=0$ and $M_{k+1}\left(m^{\prime}, n\right)<s$.

(ii) For all $k \in[0,1]$ and $m, n \in[0,3]$, if $M_{k}(m, n)=s$ then $M_{k+1}(m, n)<s$ or $M_{k+1}\left(m^{\prime}, n\right)<s\left(m^{\prime} \in[0,3] \backslash\{m\}\right)$.

(iii) $\sharp\left\{n \in[0,3] \mid M_{0}(m, n), M_{1}\left(m^{\prime}, n\right)>0\right\} \leqslant 1\left(m, m^{\prime} \in[0,3]\right)$. 
Then there exist $\mathfrak{M}_{0}, \mathfrak{M}_{1} \in\left(\begin{array}{c}{[0,3]} \\ 2\end{array}\right)$ with $\mathfrak{M}_{0} \cap \mathfrak{M}_{1}=\varnothing$ such that for each $k \in[0,1]$, if $\{m, n\}=\mathfrak{M}_{k}$ then $M_{k}(m, n)>s$.

Proof. It follows immediately from (i), (iii) that

(iv) $\sharp\left\{n \in[0,3] \mid M_{k}(m, n)>0\right\} \leqslant 2 \quad(k \in[0,1], m \in[0,3])$,

and from (ii) that

(v) $\sum_{k=0}^{1} \sharp\left\{m \in[0,3] \mid M_{k}(m, n)=s\right\} \leqslant 3 \quad(n \in[0,3])$.

Suppose that $\max _{k, m, n} M_{k}(m, n) \leqslant s$. Then by (iv), $M_{k}(m, n)=0$ or $M_{k}(m, n)=s$ $(k \in[0,1], m, n \in[0,3])$. Therefore it follows from (v) that

$$
\sum_{k, m, n} M_{k}(m, n)=\sum_{n} \sum_{k, m} M_{k}(m, n) \leqslant 4 \times 3 s=12 s .
$$

On the other hand

$$
\sum_{k, m, n} M_{k}(m, n)=\sum_{k, m} \sum_{n} M_{k}(m, n)=8 \times 2 s=16 s .
$$

This contradiction proves that there exist $i \in[0,1]$ and $m_{i} \in[0,3]$ such that $\max _{n} M_{i}\left(n, m_{i}\right)$ $>s$. By (iv) there exists $m_{i+1} \neq m_{i}$ such that $M_{i}\left(m_{i}, m_{i+1}\right)=0$. Let $m_{i}^{\prime}, m_{i+1}^{\prime} \in[0,3]$ be such that $\left\{m_{i}^{\prime}, m_{i+1}^{\prime}\right\}=[0,3] \backslash\left\{m_{i}, m_{i+1}\right\}$ and $M_{i}\left(m_{i}, m_{i+1}^{\prime}\right) \leqslant M_{i}\left(m_{i}, m_{i}^{\prime}\right)$. Suppose that $M_{i}\left(m_{i}, m_{i}^{\prime}\right) \leqslant s$. Then $M_{i}\left(m_{i}, m_{i+1}^{\prime}\right)=M_{i}\left(m_{i}, m_{i}^{\prime}\right)=s$ and so by (i) $M_{i+1}\left(m_{i+1}, m_{i+1}^{\prime}\right), M_{i+1}\left(m_{i+1}, m_{i}^{\prime}\right) \leqslant s$. Since $\max _{n} M_{i}\left(n, m_{i}\right)>s$, by (i) $M_{i+1}\left(m_{i+1}, m_{i}\right)$ $<s$. Then it follows from (iv) that $M_{i+1}\left(m_{i+1}, m_{i+1}^{\prime}\right)=M_{i+1}\left(m_{i+1}, m_{i}^{\prime}\right)=s$. Consequently $M_{i}\left(m_{i}, m_{i+1}^{\prime}\right), M_{i}\left(m_{i}, m_{i}^{\prime}\right), M_{i+1}\left(m_{i+1}, m_{i+1}^{\prime}\right), M_{i+1}\left(m_{i+1}, m_{i}^{\prime}\right)>0$ which contradicts (iii). Hence $M_{i}\left(m_{i}, m_{i}^{\prime}\right)>s$. Set $\mathfrak{M}_{k}=\left\{m_{k}, m_{k}^{\prime}\right\} \quad(k \in[0,1])$. Since $\max _{n} M_{i}(n$, $\left.m_{i}\right), M_{i}\left(m_{i}, m_{i}^{\prime}\right)>s$, it follows from (i) that $M_{i+1}(m, n)<s\left(m \in \mathfrak{M}_{i+1}, n \in \mathfrak{M}_{i}\right)$. Therefore by (iv) $M_{i+1}(m, n)>s\left(\{m, n\}=\mathfrak{M}_{i+1}\right)$. Then by (i) $M_{i}(m, n)<s(m \in$ $\left.\mathfrak{M}_{i}, n \in \mathfrak{M}_{i+1}\right)$. Hence by (iv) $M_{i}(m, n)>s\left(\{m, n\}=\mathfrak{M}_{i}\right)$.

Proposition 3.2. Let $s>0$. For each $k \in[0,1]$ let $M_{k}$ be a nonnegative $10 \times 5$ matrix such that $M_{k}(\mathfrak{M}, m)=0, \sum_{n=0}^{4} M_{k}(\mathfrak{M}, n)=2 s$ for all $\mathfrak{M} \in\left(\begin{array}{c}{[0,4]} \\ 2\end{array}\right)$ and $m \in \mathfrak{M}$. Furthermore we assume the following properties.

(i) For all $k \in[0,1], \quad n \in[0,4]$ and $\mathfrak{M}, \mathfrak{M}^{\prime} \in\left(\begin{array}{c}{[0,4]} \\ 2\end{array}\right)$ with $\mathfrak{M} \cap \mathfrak{M}^{\prime} \neq \varnothing$, if $M_{k}(\mathfrak{M}, n)>s$, then $M_{k+1}(\mathfrak{M}, n)=0$ and $M_{k+1}\left(\mathfrak{M}^{\prime}, n\right)<s$.

(ii) For all $k \in[0,1], n \in[0,4]$ and $\mathfrak{M} \in\left(\begin{array}{c}{[0,4]} \\ 2\end{array}\right)$, if $M_{k}(\mathfrak{M}, n)=s$, then

$$
M_{k+1}(\mathfrak{M}, n)<s \text { or } M_{k+1}\left(\mathfrak{M}^{\prime}, n\right)<s\left(\mathfrak{M}^{\prime} \in\left(\begin{array}{c}
{[0,4]} \\
2
\end{array}\right) \text { with } \mathfrak{M} \cap \mathfrak{M}^{\prime} \neq \varnothing\right) .
$$


(iii) $\sharp\left\{n \in[0,4] \mid M_{0}(\mathfrak{M}, n), M_{1}\left(\mathfrak{M}^{\prime}, n\right)>0\right\} \leqslant 1\left(\mathfrak{M}, \mathfrak{M}^{\prime} \in\left(\begin{array}{c}{[0,4]} \\ 2\end{array}\right)\right)$.

(iv) For all $k \in[0,1], n \in[0,4]$ and $\mathfrak{M}, \mathfrak{M}^{\prime} \in\left(\begin{array}{c}{[0,4]} \\ 2\end{array}\right)$ with $\mathfrak{M} \cap \mathfrak{M}^{\prime} \neq \varnothing$, if $M_{k}(\mathfrak{M}, n)=2 s$, then $M_{k+1}\left(\mathfrak{M}^{\prime}, n\right)=0$.

Then there exist $\mathfrak{M}_{0}, \mathfrak{M}_{1} \in\left(\begin{array}{c}{[0,4]} \\ 2\end{array}\right)$ with $\mathfrak{M}_{0} \cap \mathfrak{M}_{1}=\varnothing$ such that $M_{0}\left(\mathfrak{M}_{0}, p\right)=$ $M_{1}\left(\mathfrak{M}_{1}, p\right)=2 s$ where $p$ is the unique element of $[0,4] \backslash\left(\mathfrak{M}_{0} \cup \mathfrak{M}_{1}\right)$ and $M_{k}(\mathfrak{M}, n)=2 s$ for all $k \in[0,1], \mathfrak{M} \in\left(\begin{array}{c}{[0,4]} \\ 2\end{array}\right)$ and $n \in[0,4]$ such that $\{n\}=\mathfrak{M}_{k} \backslash \mathfrak{M}$.

Proof. For each $i \in[0,1]$ and each $m \in[0,4]$ define a $4 \times 4$ matrix $M_{i}(m)$ by

$$
M_{i}(m)\left(n, n^{\prime}\right)=M_{i}\left(\{m, n\}, n^{\prime}\right) \quad\left(n, n^{\prime} \in[0,4] \backslash\{m\}\right) .
$$

Then, when we identify the set $[0,4] \backslash\{m\}$ with $[0,3]$, the matrices $M_{0}(m)$ and $M_{1}(m)$ have all properties required by Proposition 3.1. So the proposition implies that there exist all distinct $n_{0}, n_{1}, n_{2}, n_{3} \in[0,4] \backslash\{m\}$ such that

$$
M_{0}(m)\left(n_{0}, n_{1}\right), M_{0}(m)\left(n_{1}, n_{0}\right), M_{1}(m)\left(n_{2}, n_{3}\right), M_{1}(m)\left(n_{3}, n_{2}\right)>s .
$$

Since $m$ was arbitrary, we have

$$
\sharp\left\{n \in[0,4] \mid \max _{\mathfrak{M}} M_{i}(\mathfrak{M}, n)>s\right\} \geqslant 3 \quad(i \in[0,1]) .
$$

Hence there exist $p \in[0,4]$ and $\mathfrak{M}_{0}, \mathfrak{M}_{1} \in\left(\begin{array}{c}{[0,4]} \\ 2\end{array}\right)$ such that $M_{0}\left(\mathfrak{M}_{0}, p\right), M_{1}\left(\mathfrak{M}_{1}, p\right)>$ $s$. Clearly $p \notin \mathfrak{M}_{0} \cup \mathfrak{M}_{1}$ and by (i), $\mathfrak{M}_{0} \cap \mathfrak{M}_{1}=\varnothing$. Let $\mathfrak{M}_{i}=\left\{m_{i, 0}, m_{i, 1}\right\}(i \in[0,1])$.

For each $i, j \in[0,1]$, since $M_{0}\left(\mathfrak{M}_{0}, p\right), M_{1}\left(\mathfrak{M}_{1}, p\right)>s$, it follows from (i) that $M_{i}\left(m_{i+1, j}\right)(m, p)<s\left(m \neq m_{i+1, j}\right)$ and $M_{i+1}\left(m_{i+1, j}\right)(m, p)<s\left(m \notin \mathfrak{M}_{i+1}\right)$. Therefore by Proposition 3.1

$$
M_{i+1}\left(m_{i+1, j}\right)\left(p, m_{i+1, j+1}\right), M_{i}\left(m_{i+1, j}\right)\left(m_{i, k}, m_{i, k+1}\right)>s \quad(k \in[0,1]) .
$$

Then, since $i, j$ was arbitrary, (i) implies that

$$
M_{i}(\mathfrak{M}, n)>s, M_{i+1}(\mathfrak{M}, n)=0\left(i \in[0,1], \mathfrak{M} \in\left(\begin{array}{c}
{[0,4]} \\
2
\end{array}\right),\{n\}=\mathfrak{M}_{i} \backslash \mathfrak{M}\right)
$$

Let $i, j, k \in[0,1]$. Suppose that $M_{i}\left(\mathfrak{M}_{i}, m_{i+1, j}\right)>0$. Then by (1), (iv)

$$
s<M_{i+1}\left(\left\{m_{i, k}, m_{i+1, j+1}\right\}, m_{i+1, j}\right)<2 s, \quad M_{i+1}\left(\left\{m_{i, k}, m_{i+1, j+1}\right\}, m_{i, k+1}\right)=0
$$

and so $M_{i+1}\left(\left\{m_{i, k}, m_{i+1, j+1}\right\}, p\right)>0$. But $M_{i}\left(\mathfrak{M}_{i}, m_{i+1, j}\right), M_{i}\left(\mathfrak{M}_{i}, p\right)$,

$M_{i+1}\left(\left\{m_{i, k}, m_{i+1, j+1}\right\}, m_{i+1, j}\right), M_{i+1}\left(\left\{m_{i, k}, m_{i+1, j+1}\right\}, p\right)>0$ contradicts (iii). Therefore $M_{i}\left(\mathfrak{M}_{i}, m_{i+1, j}\right)=0$. Since $j$ was arbitrary, $M_{i}\left(\mathfrak{M}_{i}, p\right)=2 s$. Then by (iv) $M_{i+1}\left(\left\{m_{i, j}, m_{i+1, k}\right\}, p\right)=0$, and since $M_{i+1}\left(\left\{m_{i, j}, m_{i+1, k}\right\}, m_{i, j+1}\right)=0$ by (1), we have

$$
M_{i+1}\left(\left\{m_{i, j}, m_{i+1, k}\right\}, m_{i+1, k+1}\right)=2 s .
$$


Since $k$ was arbitrary it follows from (2) and (iv) that

$$
M_{i}\left(\left\{p, m_{i, j}\right\}, m_{i+1,0}\right)=M_{i}\left(\left\{p, m_{i, j}\right\}, m_{i+1,1}\right)=0 .
$$

Hence

$$
M_{i}\left(\left\{p, m_{i, j}\right\}, m_{i, j+1}\right)=2 s .
$$

Since $i, j, k$ was arbitrary it follows from (2) and (3) that

$$
M_{k}(\mathfrak{M}, n)=2 s \quad\left(k \in[0,1], \mathfrak{M} \in\left(\begin{array}{c}
{[0,4]} \\
2
\end{array}\right),\{n\}=\mathfrak{M}_{k} \backslash \mathfrak{M}\right) .
$$

Lemma 3.10. Let $f \in^{\left(Y_{2} \times Y_{4}\right)} X_{1}$. If $\tau^{f}\left(F_{0}\right)=1$ then there exist $C_{0}, C_{1} \in\left(\begin{array}{c}X_{1,0} \\ 3\end{array}\right)$ with $\sharp C_{0} \cap C_{1}=1$ such that $\bigcup_{i, j \in[0,1]}\left\{f\left(\alpha_{i}\left(C_{0}, C_{1}\right), j\right)\right\}=C_{0} \cap C_{1}$.

Proof. For each $i \in[0,1]$, define a $10 \times 5$ matrix $M_{i}$ by

$$
M_{i}(\mathfrak{M}, n)=\sharp\left\{r \in S_{i}^{\prime \prime}\left(X_{1,0} \backslash \mathfrak{M}\right) \mid f(r, i)=n\right\} \quad\left(\mathfrak{M} \in\left(\begin{array}{c}
X_{1,0} \\
2
\end{array}\right), n \in X_{1,0}\right) .
$$

Then, since $\tau^{f}\left(F_{0}\right)=1$, it follows from Lemma 3.3(1), 3.5, 3.6, 3.7 and 3.8 that $M_{0}$ and $M_{1}$ satisfy the conditions of Proposition 3.2 with $s=12$. And so by the proposition, there exist $\mathfrak{M}_{0}, \mathfrak{M}_{1} \in\left(\begin{array}{c}X_{1,0} \\ 2\end{array}\right)$ with $\mathfrak{M}_{0} \cap \mathfrak{M}_{1}=\varnothing$ such that $M_{i}(\mathfrak{M}, n)=24$ for all $i \in[0,1], \mathfrak{M} \in\left(\begin{array}{c}X_{1,0} \\ 2\end{array}\right)$ and $n \in X_{1,0}$ such that $\{n\}=\mathfrak{M}_{i} \backslash \mathfrak{M}$.

Set $C_{0}=X_{1,0} \backslash \mathfrak{M}_{0}, C_{1}=X_{1,0} \backslash \mathfrak{M}_{1}$. Then $\sharp C_{0} \cap C_{1}=1$, and by the definition of $M_{0}$ and $M_{1}$, for each $i \in[0,1]$, if $C \in\left(\begin{array}{c}X_{1,0} \\ 3\end{array}\right)$ and $n \in C$ are such that $\{n\}=C \backslash C_{i}$ then $f\left(S_{i}^{\prime \prime}(C) \times\{i\}\right)=\{n\}$.

Set $a_{i}=\alpha_{i}\left(C_{0}, C_{1}\right)(i \in[0,1])$ and let $\{p\}=C_{0} \cap C_{1}$. Assume to the contrary that there exist $i, j \in[0,1]$ such that $f\left(a_{i}, j\right) \in C_{j} \backslash\{p\}$, let $f\left(a_{i}, j\right)=n$ and let $C=$ $\left\{p, n, \lambda_{j}\left(a_{i}\right)\right\}$. Clearly $\{n\}=C \backslash C_{j+1}$ and so $f\left(S_{j+1}^{\prime \prime}(C) \times\{j+1\}\right)=\{n\}$. Let $k \in[0,1]$ and $b \in S_{j+1, k}^{\prime \prime}(C)$ be such that $n \in\{p+1+2 k, p+2+2 k\}$ and $\iota_{j+1, i+1}(b) \in X_{1,0} \backslash\left(C \cup C_{j}\right)$. Then $f\left(a_{i}, j\right)=f(b, j+1)=n$ and by Lemma 3.2(4), $\left(\left(a_{i}, j, i\right),(b, j+1, i+1)\right) \notin W_{n}$. Hence, by Lemma 3.3(2), $\tau^{f}\left(F_{0}\right)=0$, which contradicts $\tau^{f}\left(F_{0}\right)=1$.

Proof of $\tau\left(F_{0}\right)=0$ : Assume to the contrary that $\tau\left(F_{0}\right)=1$. Then there exists $f \in^{\left(Y_{2} \times Y_{4}\right)} X_{1}$ such that $\tau^{f}\left(F_{0}\right)=1$. Then by Lemma 3.10 there exist $C_{0}, C_{1} \in$ $\left(\begin{array}{c}X_{1,0} \\ 3\end{array}\right)$ with $\sharp C_{0} \cap C_{1}=1$ such that $\bigcup_{i, j \in[0,1]}\left\{f\left(\alpha_{i}\left(C_{0}, C_{1}\right), j\right)\right\}=C_{0} \cap C_{1}$. Hence it follows from Lemma 3.9 that $\tau^{f}\left(F_{0}\right)=0$. This contradiction proves $\tau\left(F_{0}\right)=0$.

Since $\mu\left(F_{0}\right)=1$, this completes the proof of $\mu \nless \tau$ in Example 2.1. 


\section{References}

Hisano, H. and Maruyama, F. (1989). On the orders of max-min functionals, Bulletin of Informatics and Cybernetics 23(3-4), 163-169.

Received June 25, 2009

Revised November 5, 2010 